NBER WORKING PAPER SERIES

\title{
ACCOUNTING FOR FACTORLESS INCOME
}

\author{
Loukas Karabarbounis \\ Brent Neiman \\ Working Paper 24404 \\ http://www.nber.org/papers/w24404 \\ NATIONAL BUREAU OF ECONOMIC RESEARCH \\ 1050 Massachusetts Avenue \\ Cambridge, MA 02138 \\ March 2018, Revised June 2018
}

We thank Anhua Chen for providing exceptional research assistance and Andy Atkeson, Emmanuel Farhi, Oleg Itskhoki, Greg Kaplan, Casey Mulligan, Richard Rogerson, Matt Rognlie, and Bob Topel for helpful comments. We gratefully acknowledge the support of the National Science Foundation. Karabarbounis thanks the Alfred P. Sloan Foundation and Neiman thanks the Becker Friedman Institute at the University of Chicago for generous financial support. The views expressed herein are those of the authors and not necessarily those of the Federal Reserve Bank of Minneapolis, the Federal Reserve System, or the National Bureau of Economic Research.。

At least one co-author has disclosed a financial relationship of potential relevance for this research. Further information is available online at http://www.nber.org/papers/w24404.ack

NBER working papers are circulated for discussion and comment purposes. They have not been peer-reviewed or been subject to the review by the NBER Board of Directors that accompanies official NBER publications.

(C) 2018 by Loukas Karabarbounis and Brent Neiman. All rights reserved. Short sections of text, not to exceed two paragraphs, may be quoted without explicit permission provided that full credit, including $(\subset$ notice, is given to the source. 
Accounting for Factorless Income

Loukas Karabarbounis and Brent Neiman

NBER Working Paper No. 24404

March 2018, Revised June 2018

JEL No. E1,E22,E23,E25

\begin{abstract}
$\underline{\text { ABSTRACT }}$
Comparing U.S. GDP to the sum of measured payments to labor and imputed rental payments to capital results in a large and volatile residual or "factorless income." We analyze three common strategies of allocating and interpreting factorless income, specifically that it arises from economic profits (Case $\Pi$ ), unmeasured capital (Case K), or deviations of the rental rate of capital from standard measures based on bond returns (Case R). We are skeptical of Case $\Pi$ as it reveals a tight negative relationship between real interest rates and economic profits, leads to large fluctuations in inferred factor-augmenting technologies, and results in profits that have risen since the early 1980s but that remain lower today than in the 1960s and 1970s. Case K shows how unmeasured capital plausibly accounts for all factorless income in recent decades, but its value in the 1960s would have to be more than half of the capital stock, which we find less plausible. We view Case $\mathrm{R}$ as most promising as it leads to more stable factor shares and technology growth than the other cases, though we acknowledge that it requires an explanation for the pattern of deviations from common measures of the rental rate. Using a model with multiple sectors and types of capital, we show that our assessment of the drivers of changes in output, factor shares, and functional inequality depends critically on the interpretation of factorless income.
\end{abstract}

Loukas Karabarbounis

University of Minnesota

Department of Economics

Hanson Hall

Minneapolis, MN 55455

and NBER

loukas@umn.edu

Brent Neiman

University of Chicago

Booth School of Business

5807 South Woodlawn Avenue

Chicago, IL 60637

and NBER

brent.neiman@chicagobooth.edu 


\section{Introduction}

The value added produced in an economy equals payments accruing to labor and capital plus economic profits earned by producers selling at prices that exceed the average cost of production. Equivalently, the labor share of income, the capital share of income, and the profit share of income sum up to one. Separating these components of income is crucial in order to understand the economy's production technology, the evolution of competition across firms, and the responsiveness to various tax and regulatory policies.

Measurement of each of the three shares has proven a challenging task. Payments accruing to labor are most directly observable because they are commonly included in standard reporting for corporate financial and tax purposes. Direct measurements of the capital share and profit share are more difficult to obtain. This is because most producers own, rather than rent, their capital stocks and capital accumulation is subject to factors that are difficult to observe such as investment risk, adjustment costs, depreciation and obsolescence, and financial constraints. Additionally, various forms of capital such as brand equity and organizational capital are difficult to measure in practice. Given the relative ease of observing payments to labor, the labor share has historically been a more common focus of empirical work on factor shares than the capital share or the profit share. ${ }^{1}$

A large wave of recent work has documented a decline in the labor share starting around 1980. Karabarbounis and Neiman (2014) found this decline to be a global phenomenon, present within the majority of countries and industries around the world. ${ }^{2}$ Most analyses of the U.S. data that we are aware of, including our baseline analysis below, show that imputed payments to

\footnotetext{
${ }^{1}$ We acknowledge measurement difficulties that arise from a potential gap between the actual cost of employing labor and reported payments to labor. Measurement difficulties also arise from splitting sole proprietors' income between labor and capital. Gollin (2002) is a classic treatment on the topic, while Elsby, Hobijn, and Şahin (2013) examine this issue in the context of the recent decline in the labor share in the United States. Smith, Yagan, Zidar, and Zwick (2017) offer evidence that labor income has increasingly been misreported as capital income in U.S. S-corporations in order to minimize tax exposures, leading to an overstatement of the U.S. labor share decline. Guvenen, Mataloni, Rassier, and Ruhl (2017) find that U.S. multinationals have increasingly shifted intellectual property capital income to foreign jurisdictions with lower taxes, leading to an understatement of the U.S. labor share decline.

${ }^{2}$ Piketty and Zucman (2014) and Dao, Das, Koczan, and Lian (2017) additionally offer detailed analyses of the labor share decline for various countries and periods.
} 
capital do not rise sufficiently during this period to fully offset the measured decline in payments to labor. As a result, there is a significant amount of residual payments - or what we label "factorless income" - that, at least since the early 1980s, have been growing as a share of value added. Formally, we define factorless income as the difference between measured value added $Y$ and the sum of measured payments to labor $W L$ and imputed rental payments to capital $R K$ :

$$
\text { Factorless Income }=Y-W L-R K
$$

where we obtain value added $Y$, payments to labor $W L$, and capital $K$ from the national accounts and calculate the rental rate $R$ using a standard formula as in Hall and Jorgenson (1967).

How should one interpret factorless income? A first method, Case $\Pi$, embraces the possibility that firms have pricing power that varies over time and interprets factorless income as economic profits $\Pi .^{3}$ A second method, Case $K$, emphasizes that capital stock estimates can be sensitive to initial conditions, assumptions about depreciation and obsolescence, and unmeasured investment flows in intangibles or organizational capital and attributes factorless income to understatement of $K .{ }^{4}$ A third method, Case $R$, attributes factorless income to elements such as time-varying risk premia or financial frictions that generate a wedge between the imputed rental rate $R$ using a Hall-Jorgenson formula and the rental rate that firms perceive when making their investment decisions. ${ }^{5}$ When thinking about strategies that allocate factorless income, in short, we need to decide: "Is it $\Pi$, is it $K$, or is it $R$ ?"

The contribution of this paper is to assess the plausibility of each of these three methodologies to allocate factorless income and to highlight their consequences for our understanding of the effects of various macroeconomic trends. We begin our analyses in Section 2 in a largely modelfree environment. Aside from a standard model-based formula for the rental rate of capital, we

\footnotetext{
${ }^{3}$ Case $\Pi$ follows a long tradition including Hall (1990), Rotemberg and Woodford (1995), and Basu and Fernald (1997). More recent analyses of longer-term factor share trends such as Karabarbounis and Neiman (2014), Rognlie (2015), and Barkai (2016) also used variants of this method. Recent work related to this approach focuses on the cyclicality of the inverse of the labor share to infer the cyclicality of markups. See, for instance, Gali, Gertler, and Lopez-Salido (2007), Nekarda and Ramey (2013), Karabarbounis (2014), and Bils, Klenow, and Malin (2018).

${ }^{4}$ Examples in a large literature that follow this approach include Hall (2001), McGrattan and Prescott (2005), Atkeson and Kehoe (2005), Corrado, Hulten, and Sichel (2009), and Eisfeldt and Papanikolaou (2013).

${ }^{5}$ Such an imputation of the rental rate underlies the internal rate of return in the prominent KLEMS dataset. Similar approaches have been employed by Caselli and Feyrer (2007), Gomme, Ravikumar, and Rupert (2011), and Koh, Santaeulàlia-Llopis, and Zheng (2016).
} 
rely only on accounting identities and external measurements to ensure an internally consistent allocation of the residual income. Section 3 introduces a variant of the neoclassical growth model with monopolistic competition, multiple sectors and types of capital, and representative hand-tomouth workers and forward-looking capitalists. In Section 4, we back out the exogenous driving processes such that the model perfectly reproduces the time series of all endogenous variables in the data as interpreted by each of the three cases. We then solve for counterfactuals in which we shut down various exogenous processes driving the economy's dynamics and assess how their effects on output, factor shares, and consumption inequality between capitalists and workers depend on the strategy employed for allocating factorless income.

Case $\Pi$, where the residual is allocated to economic profits, is characterized by a tight negative comovement between the real interest rate, measured by the difference between the nominal rate on 10-year U.S. Treasuries and expected inflation, and the profit share. Mechanically, the decline in the real interest rate since the early 1980s has driven the surge in the profit share since then, a pattern emphasized in Barkai (2016) and Eggertsson, Robbins, and Wold (2018). A focus on recent decades, however, masks a significant decline in the profit share between the 1970s and the 1980s. We find that the profit share, as interpreted under Case $\Pi$, is in fact lower today than it was in the 1960s and the 1970s when real rates were also low.

Further, Case $\Pi$ requires both labor-augmenting and capital-augmenting technology to fluctuate wildly between the late 1970s and the early 1980s along with the rise and fall of the real interest rate. This extreme variability of technology is found regardless of whether the elasticity of substitution between capital and labor is above or below one. Our counterfactuals for Case $\Pi$ imply that the significant decline in markups between the 1970s and the 1980s contributed to a decline in the relative consumption of capitalists and to an increase in the labor share. The subsequent rise in profits reverses these trends after the mid 1980s. Beginning from 1960, however, the effects of markups on output, factor shares, and inequality are muted because markups did not exhibit a significant trend over the past 55 years. ${ }^{6}$

\footnotetext{
${ }^{6}$ The model we develop follows most of the related literature in assuming constant returns to scale production with no fixed costs, so the economic profit share is a fixed monotonic transformation of the markup of price over
} 
We conclude that the large swings in the profit share and the volatility in inferred factoraugmenting technologies cast doubts on the plausibility of Case $\Pi$ as a methodology to account for factorless income. De Loecker and Eeckhout (2017), however, use a different approach that also reveals a recent surge in profits. They demonstrate in Compustat data a significant rise in sales relative to the cost of goods sold (COGS) since the 1980s, a shift that underlies their estimate of an increase in markups. We demonstrate in these same data, however, that the increase in sales relative to COGS almost entirely reflects a shift in the share of operating costs that are reported as being selling, general, and administrative (SG\&A) expenses instead of COGS. Using the sum of COGS and SG\&A instead of COGS only, we find that the inferred markup is essentially flat over time. ${ }^{7}$ The shift from COGS to SG\&A - which we document also occurred in a number of other countries - is consistent with many possibilities including changing classifications of what constitutes production, outsourcing, and greater intensity in the use of intangibles in production. It is also consistent with a rise in fixed costs, which opens the possibility of increasing markups without a rise in economic profits. Given this sensitivity, we remain skeptical of Case $\Pi$.

Case $K$ attributes factorless income to unmeasured forms of capital. We calculate time series for the price, depreciation rate, and investment spending on unmeasured capital that fully account for factorless income. Many such series can be constructed, but we offer one where these variables do not behave implausibly after the 1980s. While the size of missing capital is broadly consistent with the inferred e-capital in Hall (2001) and the measured organizational capital in Eisfeldt and Papanikolaou (2013) after the 1980s, accounting for factorless income requires in the years before 1970 that the stock of missing capital be worth nearly 60 percent of the entire capital stock. Case $K$ additionally implies that output growth deviates from the growth of measured GDP in the national accounts. We demonstrate that this deviation need not be significant in most years, with growth being within 0.5 percentage point of measured growth in all but four marginal cost. As such, unless otherwise noted, we use the terms profits and markups interchangeably.

${ }^{7}$ Traina (2018) first showed the sensitivity of the markup estimate in De Loecker and Eeckhout (2017) to the split between COGS and SG\&A. Further, Gutiérrez and Philippon (2017) estimate small changes in markups using the De Loecker and Eeckhout (2017) methodology but replacing COGS with total expenses. 
years since 1960. There are some years, however, when the growth rates deviate significantly.

Case $K$ leads to far more reasonable inferences of labor-augmenting and capital-augmenting technology. While quantitative differences exist for the role of exogenous processes in driving the U.S. dynamics, the key patterns generated under Case $K$ resemble those under Case $\Pi$. For example, similar to Case $\Pi$, we find that this case also assigns the most important role in accounting for the long-term increase in consumption inequality between capitalists and workers to the slowdown of labor-augmenting technology growth.

Our last case, Case $R$, adjusts the opportunity cost of capital until it implies a rental rate such that equation (1) results in zero factorless income. We demonstrate that this adjusted opportunity cost component in firms' rental rate has been relatively stable, ranging during the last half century from levels slightly above 10 percent to levels slightly above 5 percent. We also find that this adjusted cost increased between the 1980s and the 2000s. This contrasts with the real interest rate based on U.S. Treasury prices, which jumped by nearly 10 percentage points from the late 1970s to the early 1980s, before slowly returning to the near zero levels by the 2010s. Our Case $R$ results relate closely to the conclusion in Caballero, Farhi, and Gourinchas (2017) that rising risk premia have generated a growing wedge between Treasury rates and corporate borrowing costs in recent decades. ${ }^{8}$ Among the three cases, we show that the fluctuations in both labor-augmenting and capital-augmenting technology are the smallest in Case $R .{ }^{9}$ Finally, Case $R$ attributes to the opportunity cost of capital the most important role for consumption inequality between capitalists and workers simply because this cost, and therefore capitalists' consumption growth, is higher than in the other cases.

Collectively, we view our results as tempering enthusiasm for any one of these ways to alone account for factorless income, especially so for Case $\Pi$ and Case $K$. The observation in Case $\Pi$ of a post-1980 increase in profits has called for heightened enforcement of anti-trust laws and

\footnotetext{
${ }^{8}$ Similar to our Case $\Pi$, these authors back out implied markups for various parameterizations and demonstrate that the increase in risk premia is largely robust to the behavior of markups.

${ }^{9}$ We also demonstrate that, among all three cases, Case $R$ generates the smallest gap between the growth of TFP as measured by the Solow Residual and the growth of a modified measure of TFP that uses cost shares consistent with the allocation of factorless income.
} 
calls to eliminate licensing restrictions and other barriers to entry. But our work leads to the conclusion that profits are only now returning to the historical levels of the 1960s and 1970s after having been unusually low in the 1980s and 1990s. Further, Case $\Pi$ requires a narrative tightly linking lower interest rates to rising market power at high frequencies, such as through the greater ease of financing mergers, or tightly linking greater market power to lower interest rates, such as through reduced investment demand by monopolists. Case $K$ plausibly accounts for recent movements of factorless income and, given the changing nature of production, we do not think it should be dismissed in terms of its implications for growth, factor shares, and investment. The case we explore requires an implausibly large unmeasured capital stock early in the sample in order to entirely account for factorless income. We acknowledge, however, the possibility that additional flexibility in the specification of missing capital accumulation may allow researchers to account for factorless income with less extreme values of initial missing capital. Case $R$ in many ways produces the most stable outcomes. While we find it plausible that the cost of capital perceived by firms in making their investment decisions deviates from the cost of capital one would impute based on U.S. Treasuries, we acknowledge that embracing this case more fully requires a thorough understanding of what causes time variations in this deviation and we currently do not offer such an explanation. Finally, we note that the interpretation of some key macroeconomic trends during the past 50 years proves largely invariant to the treatment of factorless income. For example, the rapid decline in the relative price of IT investment goods and the slowdown in labor-augmenting technology growth play important roles for macroeconomic dynamics in all cases.

\section{Three Strategies for Allocating Factorless Income}

In this section we analyze the three strategies for allocating factorless income. We begin by populating the terms in equation (1) used to define factorless income. Our data cover the U.S. economy and come from the Bureau of Economic Analysis (BEA), including the National Income and Product Accounts (NIPA) and Fixed Asset Tables (FAT). All our analyses begin in 1960, 
since the BEA began its measurement of a number of categories of intellectual property products in 1959 and refined its measure of research and development in 1960.

We study the private sector and therefore remove the contribution of the government sector to nominal output $Y$ and labor compensation $W L$ in equation (1). ${ }^{10}$ Some of our analyses distinguish between the business sector's value added $\left(P^{Q} Q\right)$ and profits $\left(\Pi^{Q}\right)$ and the housing sector's value added $\left(P^{H} H\right)$ and profits $\left(\Pi^{H}\right)$, where total output is $Y=p^{Q} Q+p^{H} H$ and total profits are $\Pi=\Pi^{Q}+\Pi^{H}$.

We impute rental payments to capital $R K$ in equation (1) as the sum of those accruing to each of several types of capital $j$, so that $R K=\sum_{j} R^{j} K^{j}$. Similar to our treatment of output and compensation, we remove government capital and bundle the other capital types into three mutually exclusive groups: information technology (IT) capital $(j=I)$, non-IT capital $(j=N)$, and residential or housing capital $(j=H) .{ }^{11}$ Profits in the housing sector are defined as $\Pi^{H}=P^{H} H-R^{H} K^{H}$.

Each rental rate $R^{j}$ is constructed using data on capital prices $\xi^{j}$, depreciation rates $\delta^{j}$, the real interest rate $r$, the tax rate on investment $\tau^{x}$, and the tax rate on capital $\tau^{k}$ using the formula: ${ }^{12}$

$$
R_{t}^{j}=\frac{\left(1+\tau_{t}^{x}\right) \xi_{t}^{j}}{1-\tau_{t}^{k}}\left[\left(\frac{\left(1+\tau_{t-1}^{x}\right) \xi_{t-1}^{j}}{\left(1+\tau_{t}^{x}\right) \xi_{t}^{j}}\right)\left(1+\left(1-\tau_{t}^{k}\right) r_{t}\right)-\left(1-\delta_{t}^{j}\right)-\frac{\tau_{t}^{k} \delta_{t}^{j}}{1+\tau_{t}^{x}}\right]
$$

We derive equation (2) in Section 3.4 from the optimality conditions of a representative capitalist. Our baseline measure of the real interest rate equals the nominal rate on 10-year U.S. Treasuries

\footnotetext{
${ }^{10}$ As a baseline, we measure $W L$ as compensation to employees. As we demonstrate below, this measure of the labor share produces fewer negative values for factorless income in the early 1980s than commonly used alternatives such as measures which allocate a fraction of taxes and proprietors' income to labor or labor's share of income in the corporate sector.

${ }^{11}$ IT capital includes the subtypes of information processing equipment and software. Non-IT capital includes nonresidential structures, industrial equipment, transportation equipment, other equipment, research and development and entertainment, literary, and artistic originals.

${ }^{12}$ We construct the price of capital $\xi^{j}$ for each $j$ by dividing the total nominal value of type- $j$ capital by a chained Törnqvist price index constructed using the investment price indices for each capital subtype. Similarly, the depreciation rates $\delta^{j}$ are calculated by dividing the nominal value of depreciation for that capital type, itself the sum of depreciation across subtypes, by the nominal value of capital for that capital type, which itself equals the sum of the value of capital subtypes. The tax rates come from McDaniel (2009) and are effective average tax rates calculated from national accounts. Note that in a steady state and with zero taxes, equation (2) reduces to the familiar $R=\xi(r+\delta)$.
} 


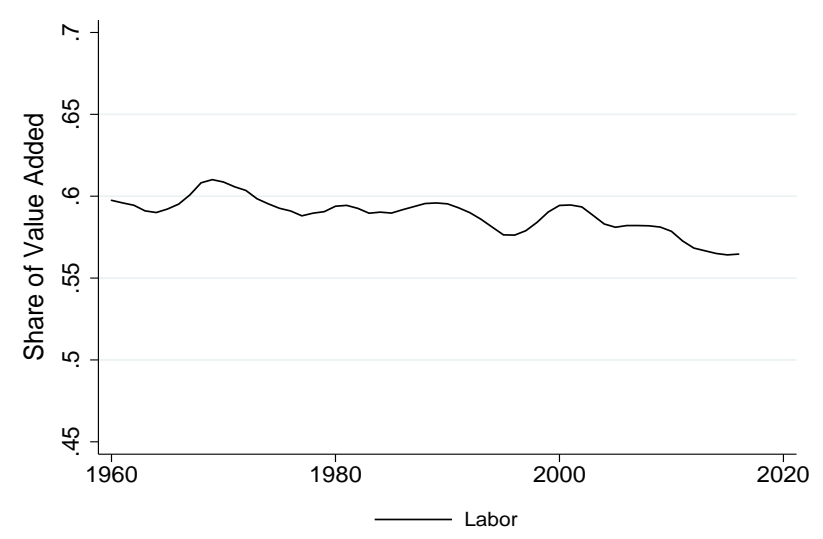

(a) Labor Share

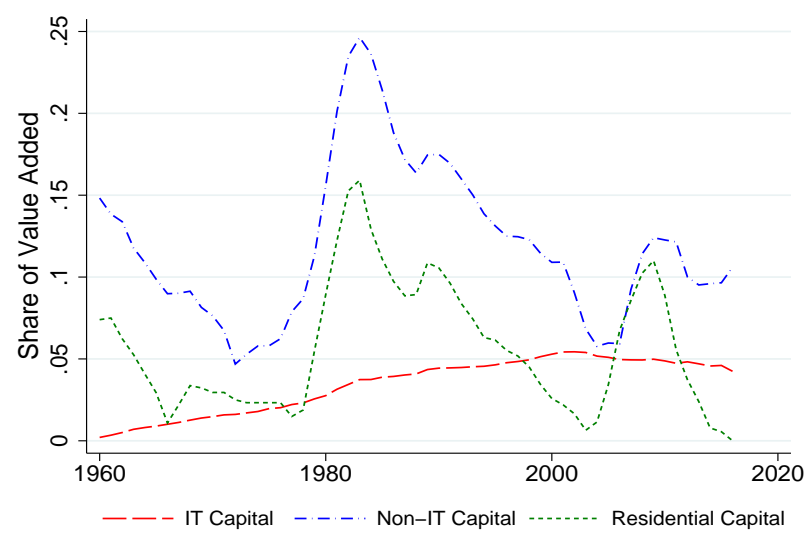

(b) Capital Shares

Figure 1: Labor and Capital Shares in U.S. Private Sector Before Allocating Residual

minus a 5-year moving average of realized inflation that proxies expected inflation. ${ }^{13}$ Additional details on our data construction are found in the Appendix.

Figure 1 plots the share of private sector value added paid to labor, or the labor share $s_{L}=W N / Y$, and the implied shares of each type of capital, $s_{K}^{j}=R^{j} K^{j} / Y$. We smooth all times series (throughout the paper) by reporting 5 -year moving averages. ${ }^{14}$ The labor share measure declines secularly, from levels near 60 percent before 1980 to 56 percent by 2016. The capital share calculations, done separately for each of the three types of capital, reveal a unique pattern for IT capital which increased from zero to about 5 percent of value added around 2000. Non-IT capital and housing capital follow essentially the same time series patterns, which highlights that they are driven by a common factor. Even in this 5-year smoothed form, the imputed capital income shares vary significantly. The sum of the labor share and the four capital shares does not necessarily equal one - the residual is factorless income's share in value added.

\section{$2.1 \quad$ Case $\Pi$}

The first approach attributes factorless income in equation (1) entirely to economic profits $\Pi$. Figure 2(a) plots the business sector's profit share, $s_{\Pi}^{Q}=\Pi^{Q} /\left(P^{Q} Q\right)$, implied by this approach.

\footnotetext{
${ }^{13}$ To fill in Treasury rates for the small number of years early in the sample where they are missing, we grow later rates backward using growth in the AAA rate.

${ }^{14}$ Here and with all time series reported as moving averages, we use 3 -year moving averages and then the 1 -year change to fill in the series for the earliest and latest two years of the sample.
} 


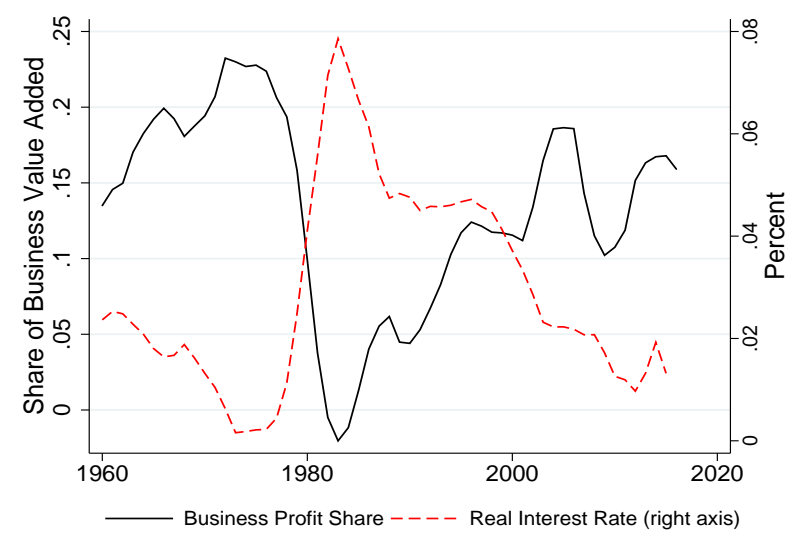

(a) Business Sector

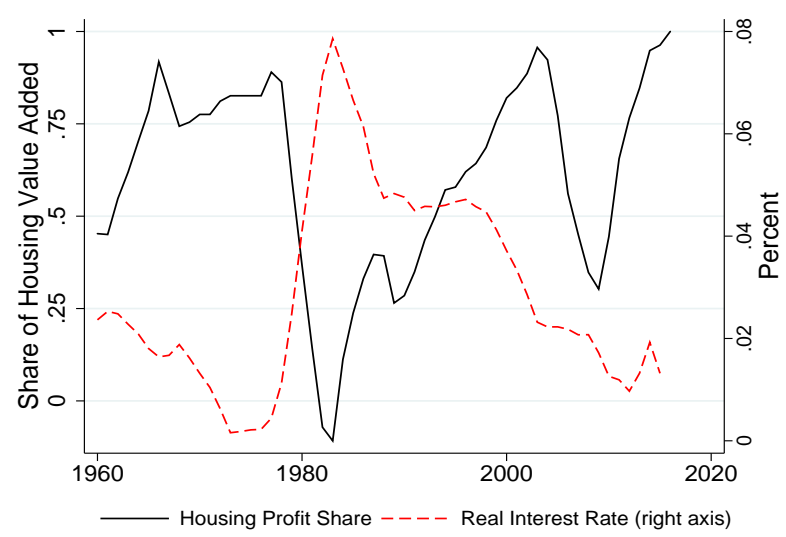

(b) Housing Sector

Figure 2: Profit Shares and Interest Rate, Case П

The solid black line plots $s_{\Pi}^{Q}$ 's 5-year moving average against the left axis and shows that between 1960 and 1980 profits averaged just below 20 percent of business value added. The profit share collapses to essentially zero in the early 1980s before reverting by the 2000s to levels averaging about 15 percent. ${ }^{15}$

This rise in the profit share after the 1980s has been noted by recent analyses such as Karabarbounis and Neiman (2014), Rognlie (2015), and Barkai (2016) in relation to the decline in the labor share. We think it is important to emphasize, however, the critical role played by the real interest rate in reaching this conclusion. The dashed red line in Figure 2(a) is plotted against the $\mathrm{y}$-axis on the right and shows the moving average of the real interest rate series used in these calculations. After hovering near low levels in the 1960s, the real interest rate jumps toward 10 percent in the early 1980s before slowly returning to the earlier low levels. ${ }^{16}$ Comparing the real interest rate with the profit share, one notes that the real interest rate and the profit share are very tightly (negatively) correlated at both high and low frequencies. The series in Figure 2(a),

\footnotetext{
${ }^{15}$ We wish to acknowledge that Matt Rognlie sent a figure documenting essentially this same pattern in private correspondence. Our methodology differs slightly from that used in Barkai (2016) due to our inclusion of taxes, different methods for smoothing, and focus on the entire business sector. The calculations, however, produce nearly identical results in terms of the time-series changes of our profit shares. When we apply his exact methodology to the business sector and lag by one-year to account for different timing conventions, the resulting series has a correlation with that in Figure 2(a) of 0.90. In the Appendix, we plot these two series together with Barkai's calculated profit share in the nonfinancial corporate sector, extended earlier than his 1984 start date.

${ }^{16}$ The timing of these changes accords well with the estimates of the real return on bonds presented by Jorda, Knoll, Kuvshinov, Schularick, and Taylor (2017) for 16 countries.
} 
for example, have a correlation of $-0.91 .{ }^{17}$

A conclusion from Figure 2(a) is that taking seriously Case $\Pi$ and the implied behavior of profits requires a narrative that links the real interest rate to the profit share. There are such possibilities. For example, cheaper credit might be crucial for facilitating corporate mergers and acquisitions in a way that increases concentration and market power. Alternatively, a growing share of firms with higher market power might desire lower investment and result in a lower real interest rate. But the linkages between these variables must be tight and operate at relatively high frequency to account for these data.

Further, while the timing of the rise in profits from the early 1980s accords relatively well with the decline in the labor share, the even higher profit share early in the sample is difficult to reconcile with the conventional U.S. macroeconomic narrative. Taken literally, these calculations imply that labor's share of business costs, $W L /\left(W L+R^{I} K^{I}+R^{N} K^{N}\right)$, averaged roughly 85 percent in the 1960s and 1970s and dropped to roughly 70 percent in the 1980s before slowly climbing back up above 80 percent after 2000 .

What are the implications of Case $\Pi$ for the housing sector? Inspired by what is essentially the same exercise in Vollrath (2017), Figure 2(b) plots the housing profit share $s_{\Pi}^{H}=1-$ $R^{H} K^{H} /\left(P^{H} H\right) .{ }^{18}$ Just as in the analyses of capital rental costs for the business sector, we combine data on the real interest rate, housing depreciation rate, price of residential capital, and the stock of housing capital to measure housing capital rental costs. We find that $s_{\Pi}^{H}$ exhibits the same basic time series patterns as $s_{\Pi}^{Q}$ but is dramatically more volatile. ${ }^{19}$ The correlation of the business profit share $s_{\Pi}^{Q}$ and the housing profit share $s_{\Pi}^{H}$ is 0.78 .

The surging profit share in housing may indeed reflect greater market power in housing rental

\footnotetext{
${ }^{17}$ The series in Figure 1(b) are much more volatile, and move more closely together, than the very similar plots of capital income shares by capital type offered in Rognlie (2015). The reason for this difference is exactly our point that Case $\Pi$ implies a tight link of capital income and profit shares to the real interest rate. Rognlie uses a constant interest rate in constructing his plotted series, so they are less volatile and comove by less.

${ }^{18}$ We note that the labor share in the housing sector is essentially zero because its value added in the national accounts is primarily composed of imputed rental income in owner-occupied housing and explicit rental payments.

${ }^{19}$ We set $R^{j}=0$ when we would otherwise impute a negative value and note that this is particularly commonly employed in the case of housing. To maintain consistency with the rest of our framework, we use the real interest rate based on 10-year Treasuries here. If we instead do this calculation using 30-year fixed rate mortgages rates, the level changes, but the time-series pattern for the most part does not.
} 


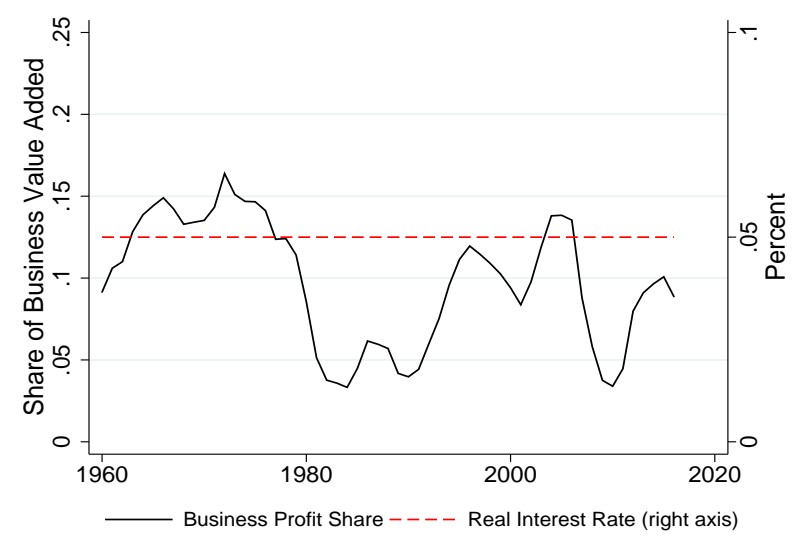

(a) Business Sector

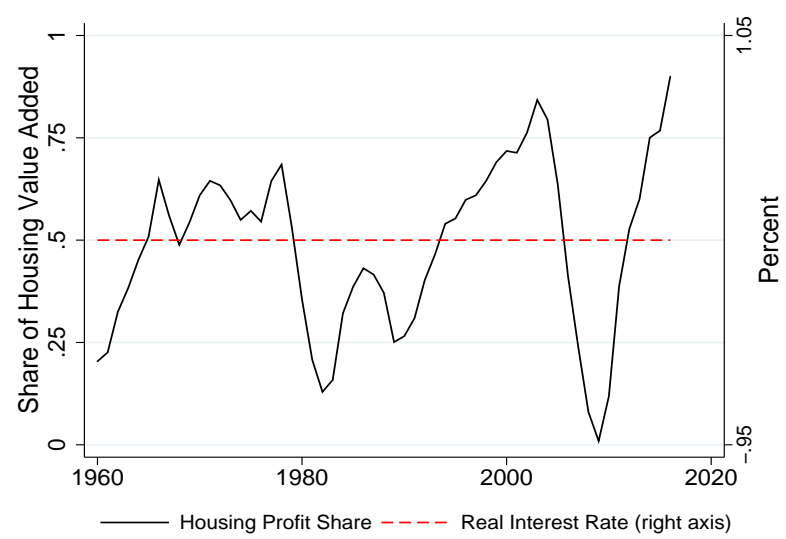

(b) Housing Sector

Figure 3: Profit Shares with Flat Interest Rate, Case $\Pi$

markets. Over the last 10 years, for example, the Blackstone group has become a landlord of enormous scale, acquiring and renting out nearly 50,000 homes. Perhaps this is representative of increasing concentration in housing markets. Further, this measure of the profit share is less suited to the housing sector than to the business sector as it disregards risk and may miss labor costs. Still, the extremely volatile path of $s_{\Pi}^{H}$ and its tight link to $r$ contribute to our doubts that Case $\Pi$ is the appropriate treatment of factorless income.

Another way to emphasize the critical role played by variations in the real interest rate for Case $\Pi$ is to calculate the profit share under this methodology but using a constant real interest rate instead of time-varying Treasury rates. Using $r=0.05$ yields the series for business and housing profit shares in Figures 3(a) and 3(b). Under this methodology the business profit share rises by only a few percentage points since the early 1980s instead of nearly 20 percentage points seen in Figure 2(a). Further, the calculated profit shares during the Great Recession return to their low levels during the 1980s. We conclude that absent the variation in the real interest rate, Case $\Pi$ would not point to surging profits.

Our basic conclusions remain largely undisturbed if we consider alternative measures of the labor share and additional alternative series for the real interest rate. First, we continue to use compensation to measure the labor share but use the Moody's AAA bond yield index instead of the 10-year Treasury yield as an input when calculating our rental rates $R^{j}$. Next, we construct 


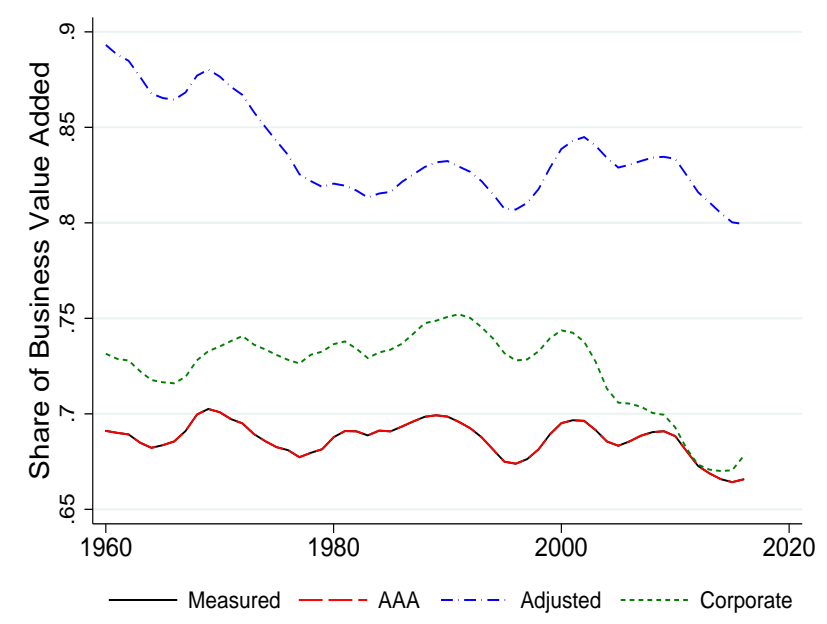

(a) Business Sector Labor Shares

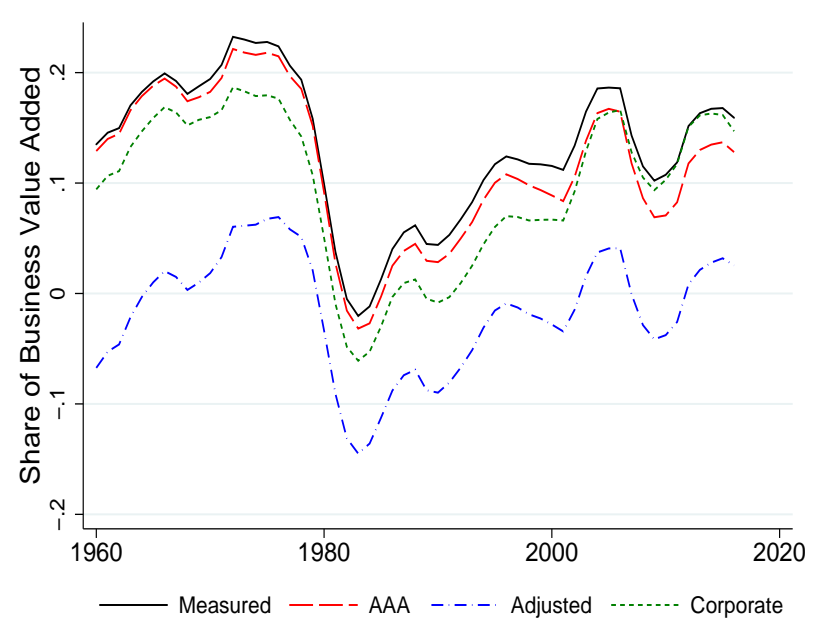

(b) Business Sector Profit Shares

Figure 4: Alternative Business Sector Labor and Profit Shares, Case $\Pi$

an "Adjusted" labor share measure by adding to our baseline measure of compensation a fraction of proprietors income and net taxes on production, where this fraction equals the share of labor compensation in the part of business value added other than proprietors income and net taxes on production. As a third case, we assume the entire business sector has a labor share equal to that measured in the corporate sector.

Figure 4(a) shows our baseline labor share series, which is not impacted by changing the real interest rate series to "AAA". The series slowly declines in recent decades but is flatter than the private sector series shown in Figure 1(a) due to the exclusion of housing, a difference uncovered and emphasized in Rognlie (2015). The "Adjusted" and "Corporate" lines exhibit somewhat different patterns, with the former dropping by most in the late 1970s and the latter dropping most since 2000 .

Figure 4(b) shows the corresponding profit share calculations. Unsurprisingly, the higher real interest rate ("AAA") and higher labor share measures ("Adjusted" and "Corporate") result in a downward shift in the level of the associated profit shares, including more periods with negative measured profit shares. However, consistent with our conclusion that the time series patterns in the real interest rate mechanically drive the evolution of the calculated profit shares, all four lines in Figure 4(b) move very closely together. 


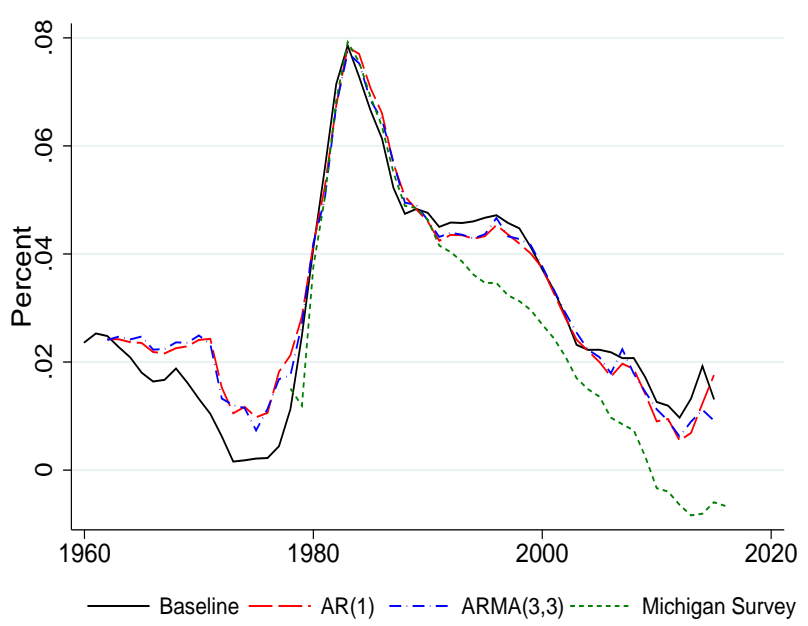

(a) Real Interest Rates

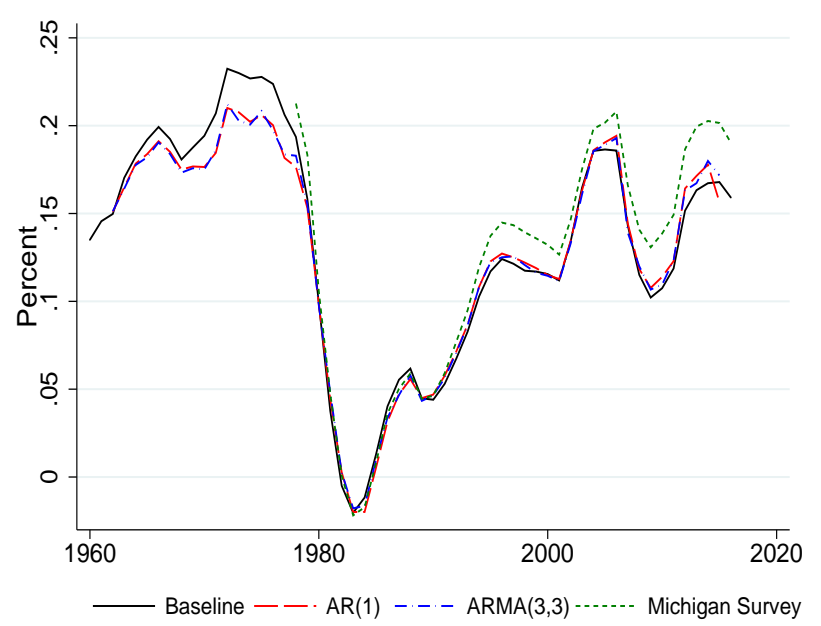

(b) Business Sector Profit Shares

Figure 5: Alternative Inflation Expectation Measures, Case $\Pi$

Figure 5 shows that our conclusions remain unchanged when we use alternative measures of inflation expectations to construct the real interest rate and the business profit share. The solid black line in Figure 5(a) shows the moving average of our baseline real interest rate, which uses a 5-year moving average of realized inflation rates to proxy for expected inflation. The corresponding profit share is shown with the solid black line in Figure 5(b). The other lines in Figure 5(a) show the moving average of real interest rates constructed using an AR(1) process, an $\operatorname{ARMA}(3,3)$ process, and the University of Michigan Survey of Consumers to measure expected inflation. ${ }^{20}$ The corresponding profits shares are plotted in Figure 5 and show essentially identical profit share dynamics.

Calculations using aggregate data to show that the sum of $s_{L}$ and $s_{K}$ is declining are not the only evidence suggesting economic profits have increased since the 1980s. De Loecker and Eeckhout (2017) apply the methodology of De Loecker and Warzynski (2012) to Compustat data and uncover a striking rise in markups from 1.18 in 1980 to 1.67 by the end of their data, reproduced as the solid black line in Figure 6(a). With constant returns and absent fixed costs, this trajectory corresponds to an increase in $s_{\Pi}^{Q}$ from about 15 percent to 40 percent. The

\footnotetext{
${ }^{20}$ Our measure of inflation is based on the price of non-housing consumption. We considered inflation processes that belong in the $\operatorname{ARMA}(p, q)$ family. The Akaike information criterion selected $(p, q)=(3,3)$ and the Bayesian information criterion selected $(p, q)=(1,0)$.
} 


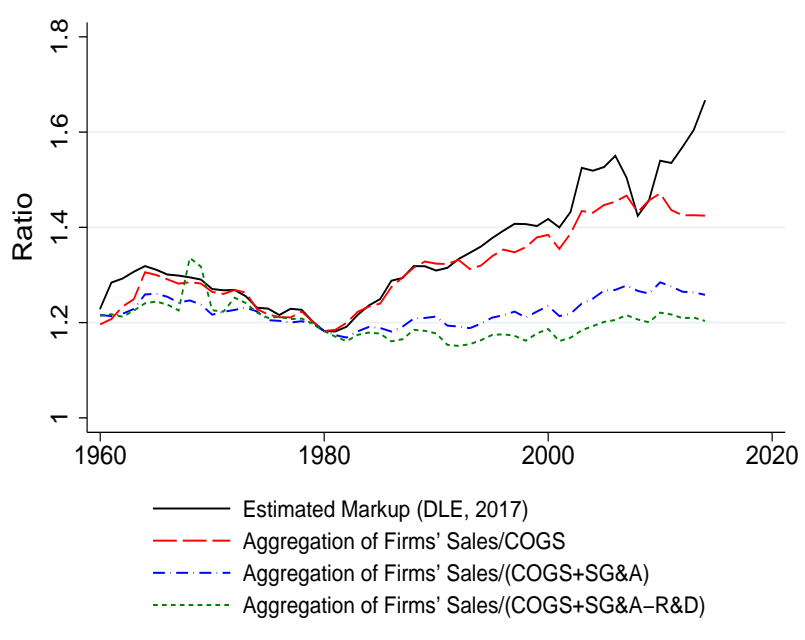

(a) Raw Data Series

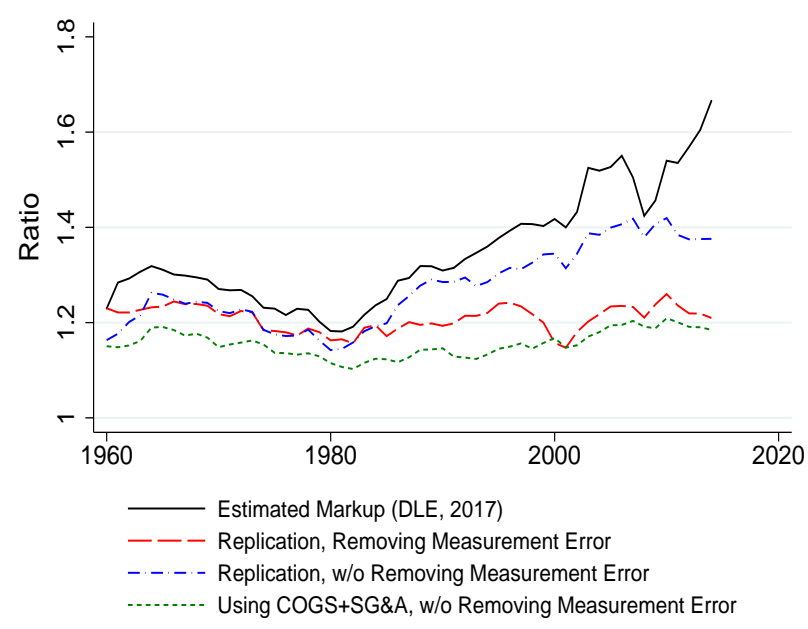

(b) Estimates

Figure 6: Markups in Compustat Data

inflection point of 1980 closely corresponds to the timing of the global labor share decline as documented in Karabarbounis and Neiman (2014).

De Loecker and Eeckhout (2017) use cost of goods sold (COGS) as their proxy for variable costs. Their methodology is more involved, but the fall of COGS relative to sales in their sample appears to be the core empirical driver of their result. The long-dashed red line in Figure 6(a) simply plots the average across firms of the sales to COGS ratio in these same data and tracks the estimated markup trajectory quite well. ${ }^{21}$

This pattern plausibly reflects forces other than growing economic profits. ${ }^{22}$ In particular, COGS suffers from some important shortcomings as a proxy for the behavior of spending on variable inputs. Compustat's data definitions describe it as including "all expenses directly allocated by the company to production, such as material, labor, and overhead..." While materials align well with the notion of variable costs, it is unclear that only variable labor costs are included and overhead is unlikely to capture variable costs in the way desired. Further, as was first noted

\footnotetext{
${ }^{21}$ We weight the ratios in this plot by firms' sales to mimic the weighting scheme used in the estimates of De Loecker and Eeckhout (2017) and multiply by a constant to normalize the series' levels in 1980.

${ }^{22}$ Autor, Dorn, Katz, Patterson, and Van Reenen (2017), Kehrig and Vincent (2017), and Hartman-Glaser, Lustig, and Zhang (2016) demonstrate that the reallocation of market share toward lower labor share firms underlies the trends of increasing concentration and declining labor share. This evidence is consistent with certain firms increasing their markups but also is consistent with technology-driven substitution toward firms operating more capital intensive production methods in an environment with stable markups. Gutiérrez and Philippon (2017) confirm that concentration has risen in the U.S. but do not find that to be the case in Europe.
} 
in this context by Traina (2018), the Compustat variable Selling, General, and Administrative Expense (SG\&A) also includes some variable costs. SG\&A is described in Compustat's data definitions as including "all commercial expenses of operation (such as, expenses not directly related to product production) incurred in the regular course of business pertaining to the securing of operating income..." Such expenses explicitly include categories like marketing or R\&D, where it is unclear if they should be variable costs in the sense desired for markup estimation, but also includes bad debt expenses, commissions, delivery expenses, lease rentals, retailer rent expenses, as well as other items that more clearly should be included as variable costs. Most importantly, Compustat itself explicitly corroborates the blurred line between COGS and SG\&A when it states that items will only be included in COGS if the reporting company does not themselves allocate them to SG\&A. Similarly, Compustat does not include items in SG\&A if the reporting company already allocates them to COGS.

The dashed blue line in Figure 6(a) shows the average across firms of the ratio of sales to the sum of COGS and SG\&A. There is a very mild increase in sales relative to this measure of operating costs. Put differently, the empirical driver of the rising markup result in Compustat data appears to be the shift in operating costs away from COGS and toward SG\&A, not a shift in operating costs relative to sales. ${ }^{23}$ This may be consistent with a rise in markups, but also might be consistent with other trends such as a rise in outsourcing (which could cause a reclassification of otherwise economically similar expenses), changing interpretations of what is meant by "production," or substitution of production activities performed by labor toward production activities performed by capital, the expenses of which may then be recorded by companies under a different category. ${ }^{24}$

Finally, we wish to emphasize that it is important to keep in mind the difference between markups of price over marginal cost and economic profits, which can be thought of as markups

\footnotetext{
${ }^{23}$ The ratio of sales to operating costs (COGS+SG\&A) fluctuated from 1.20 in 1953 to 1.14 in 1980 to 1.22 in 2014. Gutiérrez and Philippon (2017) have reported similar results when replacing COGS with total expenses.

${ }^{24}$ While not all firms that report COGS also report SG\&A, those that do represent a fairly stable share of total sales since 1980, ranging from about 72 to 82 percent. We further verified that the rise in sales to COGS looks similar in this subset of firms as in the whole set of firms, and in fact is even sharper.
} 
of price over average cost. For example, imagine that COGS perfectly captured variable costs and SG\&A perfectly captured fixed costs of production. If this was the case, the fact that COGS declines relative to Sales would suggest an increase in markups on the margin. However, the rise in SG\&A relative to Sales would, all else equal, reduce profits. Without adding more structure to quantify these relative forces, their overall impact on the average profit share is ambiguous. While markups on the margin are important for various questions of interest in economics, the average profit share is more salient for issues such as the decline in the labor share or the degree of monopoly power.

While we believe the evolution of the raw sales to COGS ratio is the proximate driver of the markup estimate in De Loecker and Eeckhout (2017), their methodology is more nuanced and sophisticated than a simple aggregation of raw operating ratios. To evaluate the sensitivity of their result to the choice of variable cost proxy, therefore, we would like to exactly implement their full methodology but substituting COGS+SG\&A for COGS as the proxy of variable costs. The solid black line in Figure 6(b) plots the headline result from De Loecker and Eeckhout (2017) and the long-dashed red line shows our best effort to exactly replicate their calculations, leveraging the publicly available replication code for De Loecker and Warzynski (2012). ${ }^{25}$ Our calculated series clearly fails to track theirs - we suspect the gap in our estimate reflects a different treatment of the variable used for the capital stock, which plays the largest role when running the first-stage non-parametric regression to purge out measurement errors. ${ }^{26}$ Indeed, when we skip that step entirely, our estimated markup series comes much closer to theirs, and is plotted in the dashed blue line. We use that same methodology but using COGS+SG\&A as our proxy for variable cost and plot the implied markup as the short-dashed green line, which confirms that substituting operating expenses for COGS reduces or eliminates the inferred rise of markups in Compustat data, consistent with the findings in Traina (2018). ${ }^{27}$ The estimated

\footnotetext{
${ }^{25}$ These series use a quasi-Newton method in the second stage estimation of industry-specific output elasticity of variable cost. Using other methods such as Nelder-Mead only changes the level of the estimated markup and continues to result in a flat time-series.

${ }^{26}$ We have tried using the perpetual inventory method, as well as directly using gross and net values for property, plant, and equipment. Our results presented here use the gross property, plant, and equipment measure for all North American firms, but little changes when using the other capital stock measures or restricting only to U.S. firms.

${ }^{27}$ We have experimented with removing expenditures associated with advertising (XAD), R\&D (XRD), pension
} 
markup rises only mildly since 1980 .

The labor share decline since 1980 is a global phenomenon that was accompanied by flat or mildly declining investment rates in most countries. ${ }^{28}$ This observation suggests that factorless income has risen in recent decades around the world. We evaluate the extent to which the ratio of sales to COGS or sales to COGS+SG\&A has trended up in other countries using data from Compustat Global. Table 1 lists, for each country with at least 100 firms in the data, the linear trend (per 10 years) in Sales/COGS and Sales/(COGS+SG\&A). There are a number of cases where the Sales/COGS ratio has significantly increased including large economies such as India, Japan, Spain, the United Kingdom, and the United States. The remaining eight countries either experienced significant declines or insignificant trends. As with the U.S. case, however, the scale and significance of the trends generally change if one instead considers Sales/(COGS+SG\&A). In that case, the positive trends in the United Kingdom and United States, for example, remain statistically significant but drop in magnitude by roughly three-quarters. Statistically significant declines emerge in China, Italy, and Korea. Whereas a simple average of the trend coefficients on Sales/COGS is 0.041, the average trend coefficient for Sales/(COGS+SG\&A) is 0.002. While Compustat's coverage in terms of time and scope varies significantly across countries, the results in Table 1 cast further doubt that increasing markups can explain the bulk of rising factorless income in recent decades.

To recap Case $\Pi$, the large residual share of value added that is neither recorded as labor compensation nor imputed as payments to capital rises rapidly from the early 1980s. Fully embracing the interpretation of this residual as rising economic profits may offer a plausible story for labor share's decline since 1980 and carries important implications for a range of topics from asset pricing to competition policy. Our analysis, however, casts doubt on this strict interpretation of factorless income as profits. First, one must acknowledge that the same methodology driving inference about rising profit shares since 1980 reveals that profit share levels in the 1960s

and retirement (XPR), and rent (XRENT), one at a time, from our measure of COGS+SG\&A and do not find meaningful differences from the case when they are included. Many firms do not report these variables separately, however, so we cannot remove them all without excluding a large majority of firms in the data.

${ }^{28}$ Chen, Karabarbounis, and Neiman (2017) document these patterns using firm-level data from many countries. 
Table 1: Trends in Markups in Compustat Global Data

\begin{tabular}{|c|c|c|c|c|c|c|}
\hline \multirow[b]{2}{*}{ Country } & \multicolumn{2}{|c|}{ Trend (per 10 years) } & \multicolumn{2}{|c|}{ Years Covered } & \multicolumn{2}{|c|}{ Firms Included } \\
\hline & Sales/COGS & Sales /(COGS+SG\&A) & Start & End & Min & Max \\
\hline Brazil & $\begin{array}{c}-0.038 \\
(0.035)\end{array}$ & $\begin{array}{c}-0.002 \\
(0.029)\end{array}$ & 1996 & 2016 & 128 & 284 \\
\hline China & $\begin{array}{l}-0.008 \\
(0.014)\end{array}$ & $\begin{array}{c}-0.021 \\
(0.007)^{* * *}\end{array}$ & 1993 & 2016 & 314 & 3683 \\
\hline France & $\begin{array}{c}-0.068 \\
(0.039)^{*}\end{array}$ & $\begin{array}{c}-0.012 \\
(0.011)\end{array}$ & 1999 & 2016 & 111 & 631 \\
\hline Germany & $\begin{array}{c}0.002 \\
(0.017)\end{array}$ & $\begin{array}{c}0.034 \\
(0.008)^{* * *}\end{array}$ & 1998 & 2016 & 119 & 668 \\
\hline India & $\begin{array}{c}0.118 \\
(0.041)^{* * *}\end{array}$ & $\begin{array}{c}0.058 \\
(0.024)^{* *}\end{array}$ & 1995 & 2016 & 630 & 2890 \\
\hline Italy & $\begin{array}{c}0.004 \\
(0.031)\end{array}$ & $\begin{array}{c}-0.057 \\
(0.018)^{* * *}\end{array}$ & 2005 & 2016 & 202 & 264 \\
\hline Japan & $\begin{array}{c}0.059 \\
(0.008)^{* * *}\end{array}$ & $\begin{array}{c}0.028 \\
(0.004)^{* * *}\end{array}$ & 1987 & 2016 & 2128 & 3894 \\
\hline Korea & $\begin{array}{c}0.000 \\
(0.009)\end{array}$ & $\begin{array}{c}-0.032 \\
(0.005)^{* * *}\end{array}$ & 1987 & 2016 & 419 & 1682 \\
\hline Russia & $\begin{array}{c}-0.133 \\
(0.097)\end{array}$ & $\begin{array}{c}-0.012 \\
(0.089)\end{array}$ & 2004 & 2016 & 127 & 245 \\
\hline Spain & $\begin{array}{c}0.274 \\
(0.117)^{* *}\end{array}$ & $\begin{array}{c}-0.026 \\
(0.044)\end{array}$ & 2005 & 2016 & 102 & 128 \\
\hline Taiwan & $\begin{array}{c}-0.051 \\
(0.026)^{* *}\end{array}$ & $\begin{array}{l}-0.021 \\
(0.018)\end{array}$ & 1997 & 2016 & 160 & 1789 \\
\hline United Kingdom & $\begin{array}{c}0.280 \\
(0.015)^{* * *}\end{array}$ & $\begin{array}{c}0.072 \\
(0.007)^{* * *}\end{array}$ & 1988 & 2016 & 183 & 1489 \\
\hline United States & $\begin{array}{c}0.088 \\
(0.004)^{* * *}\end{array}$ & $\begin{array}{c}0.021 \\
(0.002)^{* * *}\end{array}$ & 1981 & 2016 & 3136 & 8403 \\
\hline
\end{tabular}

The table summarizes estimates of the linear trend in the Sales/COGS and the Sales/(COGS+SG\&A) ratios. Standard errors are displayed in parentheses. ${ }^{* * *},{ }^{* *}$, and ${ }^{*}$ denote statistical significance at the 1,5 , and 10 percent level. 
and 1970s generally exceeded the levels reached today and this overall pattern is evident not only in the business sector but also in the housing sector. Second, one must directly link any story of economic profits to the real interest rate, as their tight negative comovement reveals the real interest rate as the mechanical driver of calculated profit shares.

\subsection{Case $K$}

We now consider a second approach which attributes factorless business income entirely to a gap between the measure of capital in the national accounts and the quantity of capital used in production. The basis for this possibility is the idea that capital stocks are imputed and potentially suffer significant measurement difficulties. The mismeasurement may reflect faulty parametric assumptions in the perpetual inventory method used to impute capital stocks but may also reflect missing investment spending, as detailed in the influential work of Corrado, Hulten, and Sichel (2009).

Certain intangible investments are particularly good candidates for missing investment spending. For example, when a chain restaurant pays advertising firms or their own marketing executives to increase awareness and positive sentiment for their brand, conventional accounts treat this spending as intermediate expenses and not as investment, much like the treatment of their spending on food. When a management consultancy pays staff to develop internal knowledge centers to organize their industry expertise, this is treated as an input to their existing production and not as an investment in the firm's capital stock. The U.S. BEA explicitly recognized the importance of various misclassified investment expenditures when they changed their treatment of software in 1999 and of R\&D and artistic originals in 2013 and, accordingly, revised upward their historical series for investment and capital stocks. ${ }^{29}$

Let $X^{U}$ equal the real value and $\xi^{U}$ equal the price of unmeasured investment, which accumulates into an unmeasured capital stock $K^{U}$ with an associated rental rate $R^{U}$. These magnitudes

\footnotetext{
${ }^{29}$ See Koh, Santaeulàlia-Llopis, and Zheng (2016) for a helpful primer on these changes and their impact on the measured labor share decline.
} 
are related to measured income according to:

$$
\tilde{Y}=Y+\xi^{U} X^{U}=W L+R^{I} K^{I}+R^{N} K^{N}+R^{H} K^{H}+\Pi+R^{U} K^{U}
$$

where $\tilde{Y}$ is unmeasured (or "revised") output which may differ from measured GDP $Y$.

To see how unmeasured investment matters for factorless income and output, consider two extreme cases. First, consider the case where there is unmeasured capital in the economy accumulated from past investment flows, so $R^{U} K^{U}>0$, but current investment spending of this type equals zero, $\xi^{U} X^{U}=0$. In this case, output is correctly measured and $\tilde{Y}=Y$. Capital income, however, is underestimated by $R^{U} K^{U}$. Alternatively, imagine that $R^{U} K^{U}=0$ in some year, but there is unmeasured investment and $\xi^{U} X^{U}>0$. This means that output is larger than measured GDP, but standard measures of $R K$ correctly capture capital income. In cases in between these extremes both capital income and output will be mismeasured.

We can rearrange equation (3) so the left hand side equals the gap between unmeasured capital income and unmeasured investment spending and the right hand side contains only measured income terms and economic profits:

$$
R^{U} K^{U}-\xi^{U} X^{U}=Y-W L-R^{I} K^{I}-R^{N} K^{N}-R^{H} K^{H}-\Pi^{Q}-\Pi^{H}
$$

For any given paths of business sector profits $\Pi^{Q}$ and housing sector profits $\Pi^{H}$, there will generally be many possible paths of $R^{U}, K^{U}, \xi^{U}$, and $X^{U}$ that satisfy equation (4) for the years covered in our data. Most such paths, however, may not be economically sensible. To put more discipline on our exercise, we additionally require that $R^{U}$ is generated like the other rental rates $R^{j}$ in equation (2) and that capital and investment are linked through a linear capital accumulation equation $K_{t+1}^{U}=\left(1-\delta^{U}\right) K_{t}^{U}+X_{t}^{U}$.

We solve for one set of paths $\left\{R^{U}, K^{U}, \xi^{U}, X^{U}\right\}$ as follows. First, we create a grid with different combinations of business profit share levels $s_{\Pi}^{Q}$, depreciation rates $\delta^{U}$, and values of the capital stock relative to measured GDP in 2010 (chosen because prices are normalized to one in 2009). For each combination of $\left\{s_{\Pi}^{Q}, \delta^{U},\left(K^{U} / Y\right)_{2010}\right\}$, we consider a number of values for $\xi_{2010}^{U}$, the price of investment in 2010. Each resulting value of $\xi^{U}$ in 2010 can be used to calculate a 
value for $R^{U}$ in 2010 using equation (2) since $\xi_{2009}^{U}=1$. Since the right hand side variables of equation (4) are then all known for 2010 (we keep $\Pi^{H}$ at its values from Case $\Pi$ ), and we have assumed values for $R^{U} K^{U}$ and $\xi^{U}$ on the left hand side, we can then back out the value for the remaining left hand side term $X_{2010}^{U}$, real investment in unmeasured capital in 2010. Using the capital accumulation equation, we then calculate $K^{U}$ in 2011 and start the sequence again.

We iterate forward in this way through 2015 and do the same in reverse to iterate backward from 2010 to 1960. This results in a series of thousands of possible paths for each node of the grid $\left\{s_{\pi}^{Q}, \delta^{U},\left(K^{U} / Y\right)_{2009}\right\}$. From all those possibilities, we select the paths such that investment is non-negative and where the variance and magnitude of the price and stock of unmeasured capital is minimized. Additional details on our exact algorithm and selection criteria are found in the Appendix.

Figure 7 plots the 5-year moving average of key magnitudes describing the unmeasured investment where $s_{\Pi}^{Q}=0.06$ and $\delta^{U}=0.05$. Figure 7 (a) shows a path for the price of unmeasured investment in terms of the price of non-housing consumption. After having essentially flat or slightly declining investment prices from 1960 to 1980, the price grows rapidly at almost 13 percent per year until 2000. Prices are then fairly flat through 2010 and have declined at about 6 percent per year since then.

This price path may seem unusual, but as shown in Figure 7(a), the rate of price change is orders of magnitude smaller than that of IT capital. Further, though both IT and non-IT depreciation rates evolve over time in the data, we reduce our degrees of freedom and assume a constant value for $\delta^{U}$. Allowing more flexibility in our choice of $\delta^{U}$ (or, similarly, allowing $s_{\Pi}^{Q}$ to fluctuate around a constant level) would likely allow us to find paths of $\xi^{U}$ with a bit less unusual behavior. Combined with the underlying real interest rate and depreciation rate, this price path translates into a path for the rental rate of unmeasured capital $R^{U}$, plotted in Figure 7(b), which comoves negatively with the non-IT rental rate. It has generally risen from near zero in the 1960s to nearly 15 percent in recent years.

Figure 7(c) shows investment spending in each type of capital relative to revised output $\tilde{Y}$. It 


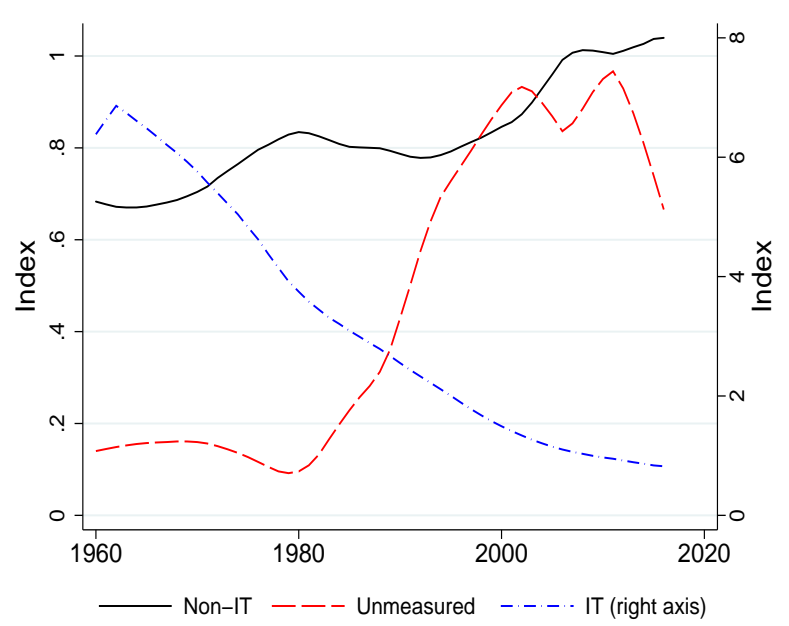

(a) Business Investment Prices

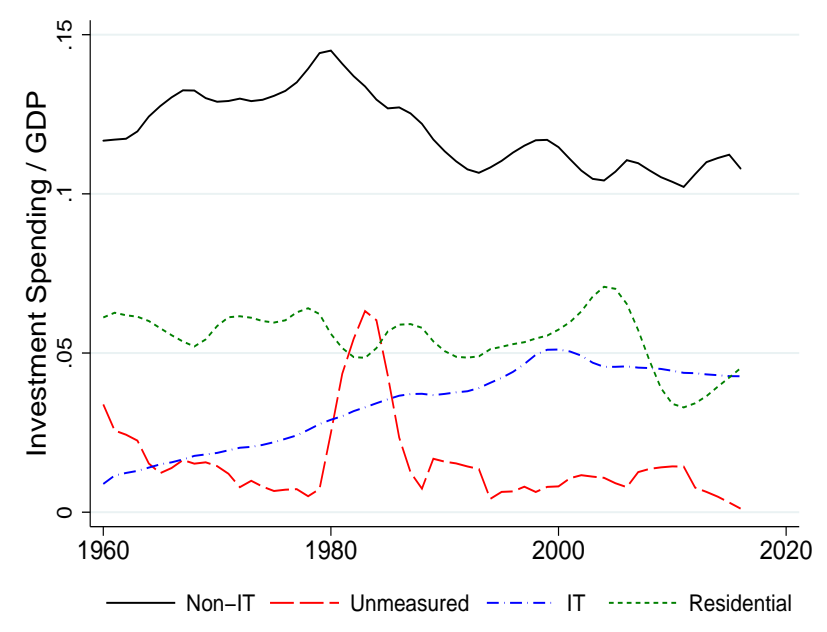

(c) Investment Rates

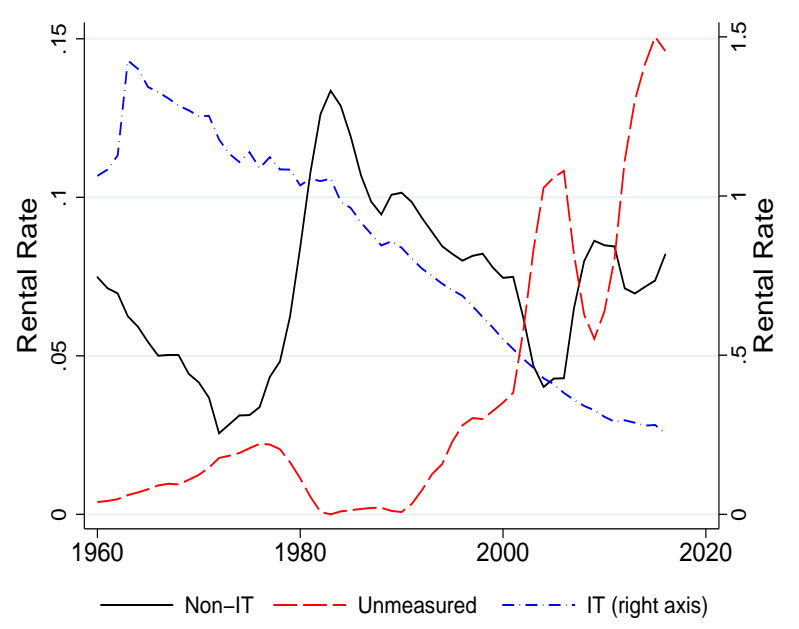

(b) Business rental rates

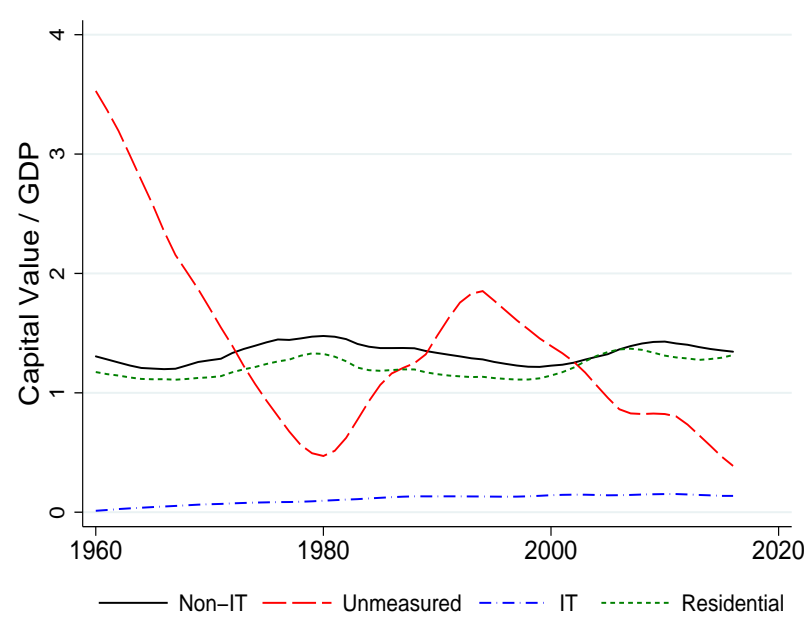

(d) Value of Capital Stocks / GDP

Figure 7: Hypothetical Paths Governing Missing Investment and Capital, Case $K$

shows that investment spending on unmeasured capital need not be particularly large to account for factorless income. As shown in the figure, there is a surge in early 1980s investment in unmeasured capital. Recall that factorless income, or what Case $\Pi$ calls profits, is high prior to the early 1980s at nearly 25 percent of GDP and then plunges to less than zero before growing back to levels seen earlier. This investment surge in the early 1980s, combined with the rising rental rates from the 1990s onward as seen in Figure 7(b), helps match that pattern.

Finally, Figure $7(\mathrm{~d})$ plots the value of each capital stock relative to output, $\xi^{j} K^{j} / \tilde{Y}$. The figure shows that the value of this missing capital stock is at times quite large. Early in the 


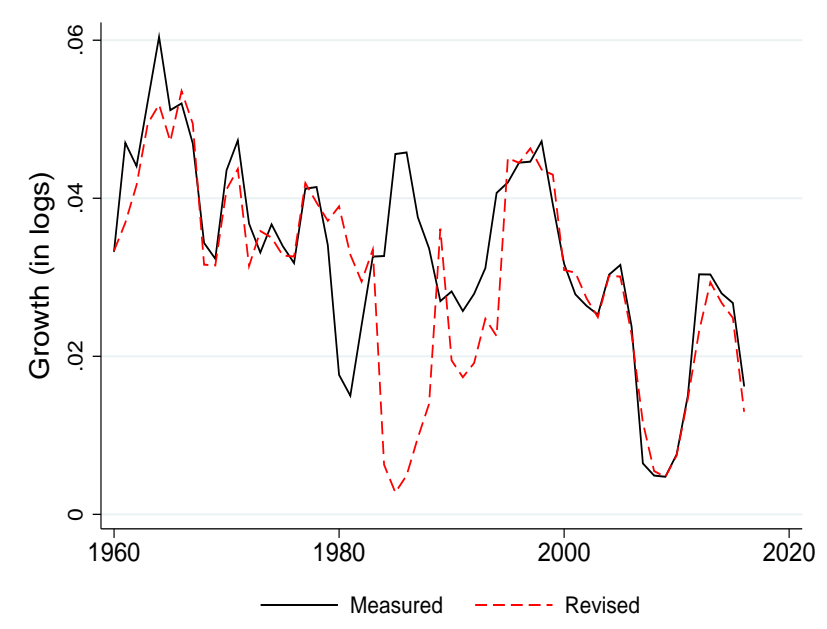

(a) Log Real GDP Growth

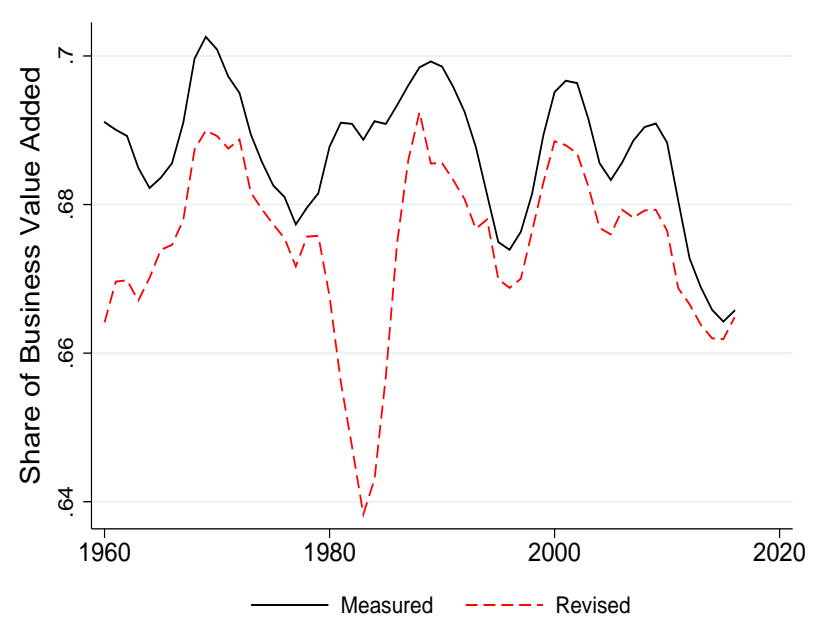

(b) Business Sector Labor Shares

Figure 8: Implications of Mismeasured GDP, Case $K$

sample, the capital stock is worth roughly three times output and accounts for more than half of the value of the capital stock. From 1970 onward, however, this capital would only need to be worth between one-half and twice of output. Over that period, unmeasured capital accounts for roughly 30 percent of the value of all capital in the economy and roughly 40 percent of all business capital. $^{30}$

Under Case $K$, the deviation of revised output from measured GDP equals unmeasured investment spending, which Figure 7(c) shows to be quite low. Figure 8(a) compares moving averages of log changes in the two (real) output series, which are visually quite similar except for the key periods in the late 1970s and early 1980s. The 25th to 75 th percentile range in the distribution of deviations of the two growth rates is -0.5 percentage point to 0.6 percentage point, with a median deviation equal to zero. There are some years, most notably 1982, in which the gap is large. Such gaps often represent shifts in the timing of growth periods, and indeed, measured growth during the subsequent two years exceeds revised growth by a total of

\footnotetext{
${ }^{30}$ We note that the selection procedure in our algorithm plays a role in this. We focus on paths where nominal investment spending is small so GDP mismeasurement, discussed below, is also small. A consequence of this, however, is that there is little scope for the unmeasured capital stock to quickly grow prior to periods in which there is large or increasing factorless income. The initial stock of unmeasured capital therefore, according to this particular procedure, must be large. With less emphasis on minimizing the scale of unmeasured investment spending, we would likely be able to moderate the scale of initial unmeasured capital.
} 
8.4 percent, undoing some of the 1982 gap.

An implication of Case $K$ is that the path of the revised labor share differs from that of the measured labor share. Figure 8(b) compares moving averages of these series. Though they largely move together, the revised labor share declines significantly in the early 1980s due to the surge in output from investment in unmeasured capital at that time. As a result, the revised labor share in the business sector does not end at a historic low as does the measured business labor share. Both series however, exhibit almost parallel trends starting from the mid 1980s.

The magnitude of our estimates of unmeasured investment and capital for the post-1980 period is only moderately larger than other estimates in the literature. Hall (2001) examines the relationship between the stock market and intangibles he referred to as "e-capital" from technical resources and organizational know-how. He argues that e-capital accumulation from the 1990s resulted in an e-capital stock roughly 50 percent as large as measured GDP by 2000. McGrattan and Prescott (2005) attribute the gap between income and the sum of observed compensation to labor and imputed income to measured capital (what we call factorless income) to payments to intangibles. Their methodology restricts to balanced growth paths and implies a stock of missing capital equal to roughly two-thirds of output. Atkeson and Kehoe (2005) apply the same methodology for the U.S. manufacturing sector and also arrive at the same estimate. Eisfeldt and Papanikolaou (2013) construct organizational capital from SG\&A expenses and the perpetual inventory method. They find that the value of organizational capital typically exceeds that of physical capital.

Corrado, Hulten, and Sichel (2009) base their approach on more direct measurements. They show that, by 2000, investments in brand values and firm-specific resources account for up to 6 percent of measured output. But they assume these intangible capital stocks depreciate rapidly and set their values equal to zero in the decades preceding our data. Their implied estimates for the scale of these capital stocks are far smaller, therefore, than what we show in Figure 7(d). Barkai (2016) benchmarks in part to their work and argues that the size of missing capital would have to be implausibly large in order to account for factorless income. His calculations further 
assume that missing investment exceeds depreciation. By contrast, our estimated capital stock does not surge after 1980 in part because we allow the rate of investment to fall below the rate of depreciation.

\subsection{Case $R$}

We now consider a third approach which attributes factorless income entirely to the rental rate of capital faced by firms. For this analysis, we focus only on the business sector and ignore housing. Denoting by $\tilde{R}^{j}$ the revised rental rates (which may differ from the $R^{j}$ used to calculate factorless income), we write:

$$
P^{Q} Q=W N+\tilde{R}^{I} K^{I}+\tilde{R}^{N} K^{N}+\Pi^{Q}
$$

where unlike Case $\Pi$ the level of business profits $\Pi^{Q}$ is simply taken as given (i.e. chosen based on external information) and unlike Case $K$ there is no missing capital. There are multiple ways to calculate $\tilde{R}^{j}$ such that equation (5) holds given values for $P^{Q} Q, W N, K^{j}$, and $\Pi^{Q}$. To add more discipline to the exercise, we solve for the unique revised real interest rate $\tilde{r}$ such that the revised rental rates $\tilde{R}^{j}$ calculated according to equation (2) satisfy equation (5). The gap between $\tilde{r}$ and our measure $r$ taken from Treasury yields and used in the other cases can be thought of as standing in for a time-varying risk premium or the impact of particular forms of adjustment costs or financial frictions. In our calculations, we set $\Pi^{Q}$ to generate a constant $s_{\Pi}^{Q}=0.06$, the value also used in Case $K$.

Figure 9 compares 5-year moving averages of the resulting revised interest and rental rates (labeled "Revised" and plotted in dashed red lines) with those calculated using the 10-year Treasury yields (labeled "Measured" and plotted in solid black lines). Figure 9(a) offers the intuitive result that $\tilde{r}$ is generally higher than $r$ because it absorbs factorless income. Additionally, $\tilde{r}$ does not decline in parallel with $r$ after 1990s because higher levels of $\tilde{r}$ account for the increasing factorless income as a share of value added.

Given the lack of decline in $\tilde{r}$, the revised rental rates $\tilde{R}^{j}$ become flatter relative to the measured rental rates $R^{j}$ calculated with $r$. The change in the real interest rate underlying 


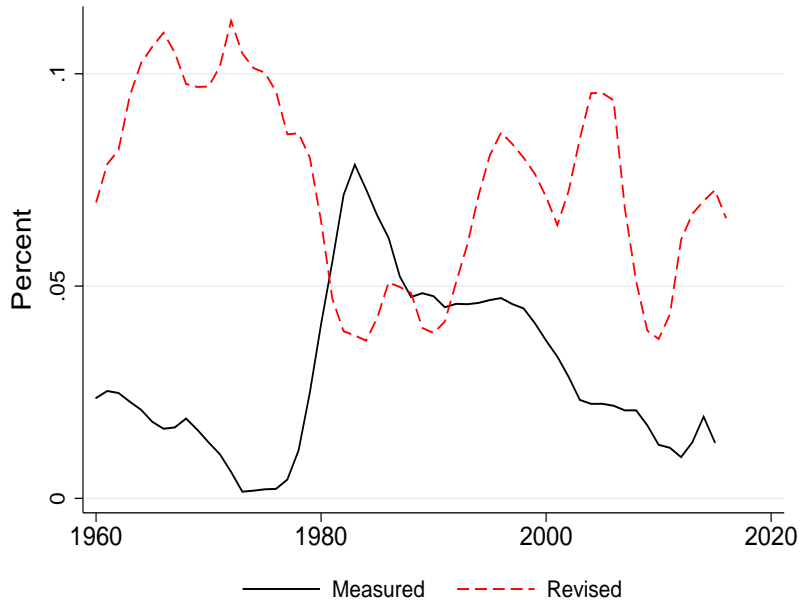

(a) Real Interest Rate

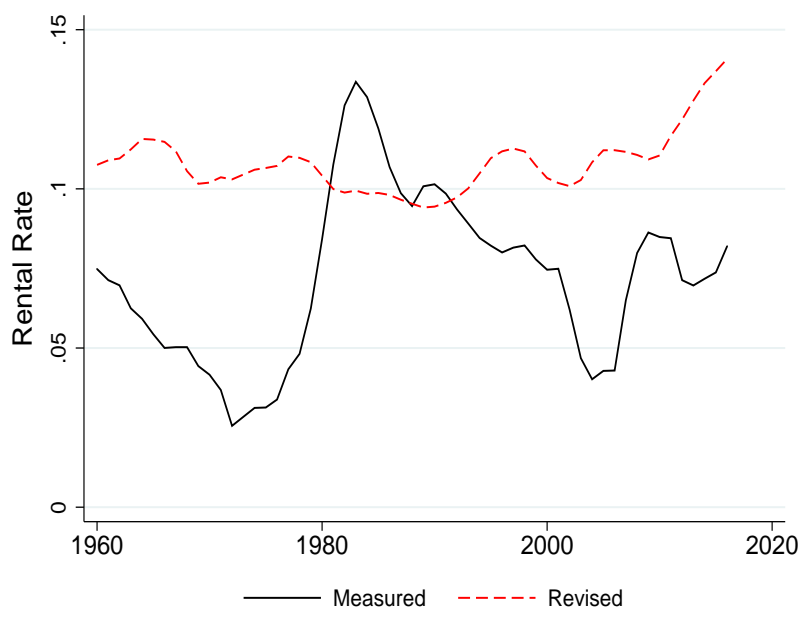

(c) Non-IT Rental Rate

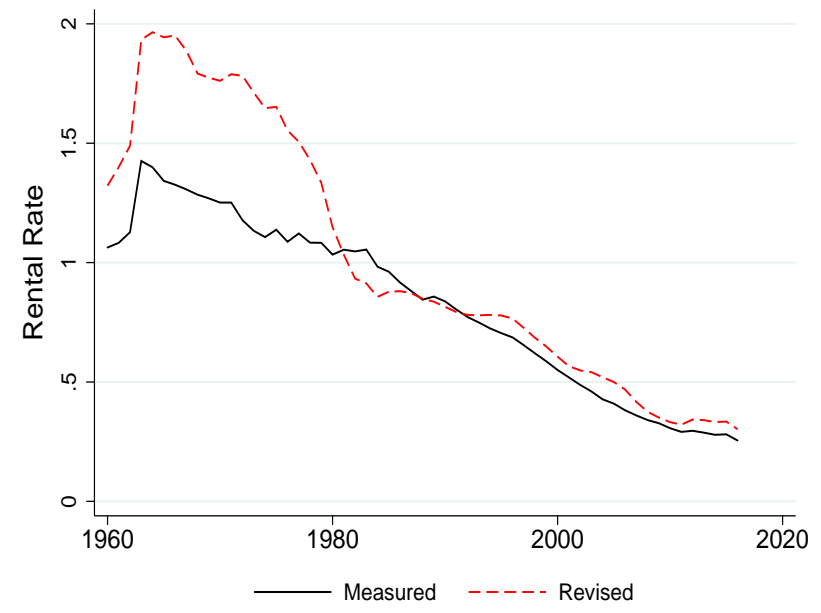

(b) IT Rental Rate

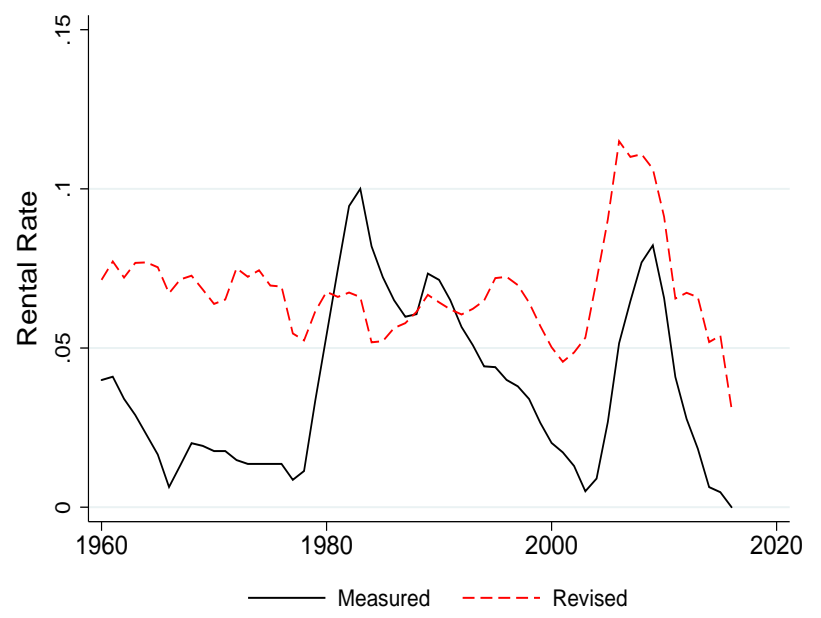

(d) Housing Rental Rate

Figure 9: Measured and Revised Real Interest Rate and Rental Rates, Case $R$

the construction of the rental rates does not impact IT, non-IT, and housing capital income in the same way because these assets have different depreciation rates and investment price changes. The higher depreciation rate on IT capital means that the real interest rate is a less important driver of its rental rate compared with that of non-IT capital. The rental rate of IT capital declines rapidly due to the decline in the price of IT investment goods $\xi^{I}$, often attributed to productivity improvements in the development of communication, computers, and semiconductor technologies. Non-IT and housing rental rates, plotted in Figures 9(c) and 9(d), are more sensitive to the measure of the real interest rate. Relative to Case $\Pi$, these revised 
rental rates are all flatter after the 1980s.

Is there other evidence that risk premia or factors other than profits have caused an increasing wedge between Treasury rates and the opportunity cost of capital perceived by firms when making their investment decisions? ${ }^{31}$ Our Case $R$ results relate closely to the conclusion in Caballero, Farhi, and Gourinchas (2017) that rising risk premia have generated a growing wedge between Treasury rates and corporate borrowing costs in recent decades. Their calibration exercises suggest that absent these rising risk premia since 1980, changes in the Treasury rates would have produced implausible factor share movements given the standard range of elasticities they consider. In a sample of 16 economies, the estimates of Jorda, Knoll, Kuvshinov, Schularick, and Taylor (2017) suggest that the gap between the return on risky equity and housing and the return on safe assets has slightly increased between the 1990s and the 2010s. We acknowledge that the evidence for rising risk premia is mixed. Earlier research by Jagannathan, McGrattan, and Scherbina (2000) and Fama and French (2002) documents a decline in the U.S. equity premium between 1980 and 2000. More recent work by Duarte and Rosa (2015), however, demonstrates that the first principle component of 20 model-based estimates of the equity risk premium has increased dramatically since the 2000s and reached again the historically high levels observed during the late 1970 s.

\subsection{Implications for Total Factor Productivity}

What are the implications of each of our three cases for productivity? Macroeconomists calculate Solow Residuals to try to infer the rate of growth of technology or TFP. Appealing to the assumption of perfect competition, the convention is to weight the growth of labor and capital input by the labor share and one minus the labor share. For the business sector, we write the growth of the standard or "Naive" measure of TFP as:

$$
d \ln \mathrm{TFP}_{\text {Naive }}=d \ln Q-s_{L}^{Q} \times d \ln L-\left(1-s_{L}^{Q}\right) \sum_{j \in\{I, N\}} \frac{s_{K^{j}}^{Q}}{s_{K}^{Q}} \times d \ln K^{j}
$$

\footnotetext{
${ }^{31}$ Following Barkai (2016), we have also calculated real interest rates using Moody's AAA borrowing rates. This change did not meaningfully alter any of our conclusions, but in that case the wedge calculated in Case $R$ should be interpreted as a risk premium over those AAA bond rates.
} 


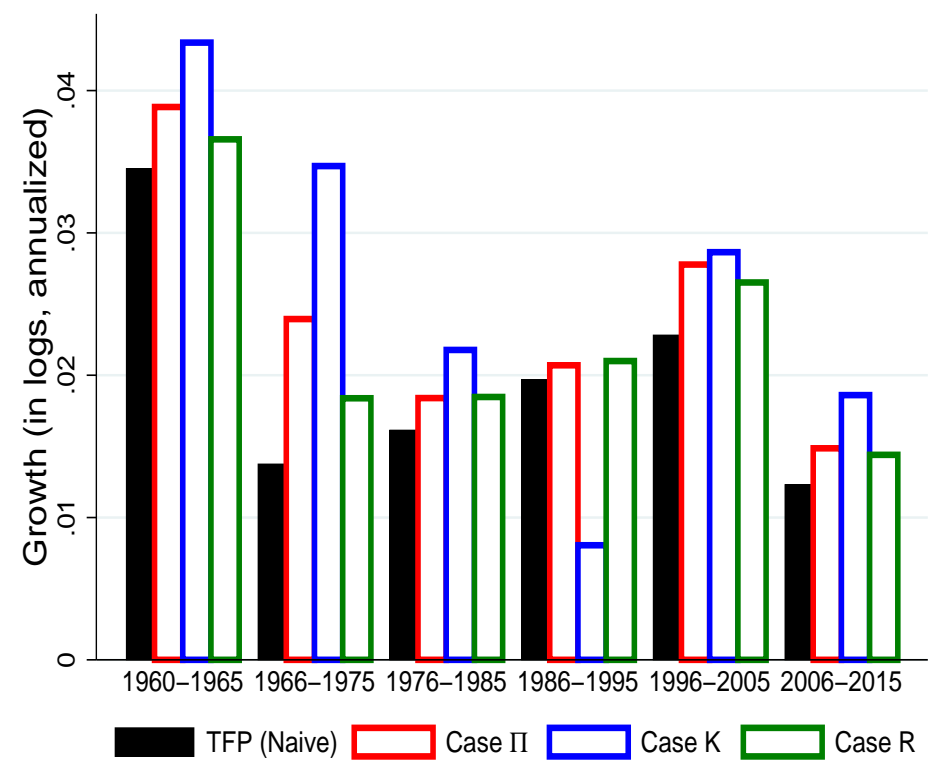

Figure 10: Naive TFP and Modified Solow Residuals in U.S. Business Sector

where we also follow the convention in creating an index of business capital growth as a capital $-j$ share weighted average of growth in IT and Non-IT capital stocks.

As discussed in Hall (1990), Basu and Fernald (2002), and Fernald and Neiman (2011), when measured factor shares do not equal the true factor shares in costs, due to imperfect competition or measurement error, this standard Solow Residual will fail to approximate technology. Rather, one must use revised factor shares of cost in what is called a "Modified" Solow residual:

$$
d \ln \mathrm{TFP}_{\text {Modified }}=d \ln Q-\frac{s_{L}^{Q}}{1-s_{\Pi}^{Q}} \times d \ln L-\sum_{j \in\{I, N, U\}} \frac{s_{K^{j}}^{Q}}{1-s_{\Pi}^{Q}} \times d \ln K^{j} .
$$

All three of our interpretations of factorless income imply that modified TFP in equation (7) will differ from the naive TFP measure in equation (6). In Case $\Pi$, the primary difference arises as the large and fluctuating profit share $s_{\Pi}^{Q}$ drives a wedge between labor's share of costs and labor's share of revenues. Case $K$ and Case $R$ also have non-zero profit shares, though they are typically smaller and are constant. Further, under Case $K$, modified TFP will differ from the naive measure because of unmeasured value added and unmeasured capital. Finally, under Case $R$, modified TFP will differ from the naive measure because the revised rental rates for IT and Non-IT capital changes their relative shares in costs. 
The solid black bars in Figure 10 report the average growth rates of the naive TFP measure in equation (6) for 1960-1965 and subsequent 10-year periods to $2015 .^{32}$ The evolution of these bars is consistent with the conventional U.S. productivity growth narrative, with high rates in the 60s slowing down in the early 70s, and a short-lived burst during the mid-1990s collapsing in the mid-2000s. The hollow red bars report the modified TFP measure in equation (7) under the Case $\Pi$ interpretation of factorless income. Capital input has generally grown faster than labor input, so the large markups in this case imply that the naive measure understates technology growth. The extent of this difference varies over time. Case $\Pi$ suggests that in the most recent 10-year period, the naive measure implies growth rates 20 percent lower than what would be inferred from the modified Solow Residual. It also suggests that during the 1966-1975 period a period often considered the start of the "Great Productivity Slowdown" - the modified TFP measure of technology growth was almost twice the rate implied by the naive measure.

For Case K, the blue bars in Figure 10 show that, in all periods aside from 1986-1995, the growth of the naive measure of TFP is significantly lower than the growth implied by the modified measures. The basic logic for this difference is that GDP growth is not meaningfully impacted by unmeasured investments but the stock of capital is. Given the unmeasured capital stock is generally falling according to Case $K$, the capital input growth used in equation (6) is too high.

For Case $R$, the green bars show the smallest gap between the naive and the modified measures of TFP. Attributing a growing fraction of income to rental payments, as Case $R$ does, tends to decrease the growth of modified TFP relative to that of naive TFP. The small but non-zero profit share used in that case tends to increase the growth of modified TFP relative to naive TFP. These forces tend to offset each other, causing the naive measure of TFP to be closest to the modified measure of TFP in Case $R$.

\footnotetext{
${ }^{32}$ In performing the calculations, factor shares are calculated as the average values across adjacent periods corresponding to a Törnqvist index once chained together.
} 


\subsection{Taking Stock}

To summarize our results, we have developed three strategies to allocate factorless income in an environment which, aside from a standard model-based formula for the rental rate of capital, relies on accounting identities to ensure an internally consistent allocation of the residual income. Case $\Pi$ requires a tight link between real interest rates and markups. While it implies rising profits from the early 1980s, it suggests that current profit levels remain below their levels in the 1960s and 1970s. Our implementation of Case K leads to plausible results after the 1980s, but requires that unmeasured capital in the 1960s comprises more than half of total capital. Using a different selection criterion might allow for a smaller unmeasured capital stock in 1960 but at a cost or requiring more unmeasured flows later in the sample. Case $R$ seems most promising as it stabilizes relative capital shares and preserves the traditional narrative of TFP's evolution. We recognize, however, that more evidence of rising risk premia or other wedges in firm's opportunity cost of capital is required before one more fully embraces this case. We next introduce a variant of the growth model with capital accumulation to make more progress at assessing the plausibility of these three interpretations of factorless income and to evaluate their implications for a richer set of macroeconomic outcomes.

\section{A Multi-Sector Model with Multiple Capital Types}

We consider an economy with multiple sectors and multiple types of capital. ${ }^{33}$ The business sector uses labor, IT capital, non-IT capital, and intangible or organizational capital - which is not measured in the fixed asset tables - to produce consumption and investment goods. The housing sector uses residential capital to produce housing services. The horizon is infinite and there is no aggregate uncertainty. The economy is populated by workers and capitalists who have perfect foresight about the evolution of all exogenous driving processes. The economy is

\footnotetext{
${ }^{33}$ Greenwood, Hercowitz, and Krusell (1997) consider the macroeconomic effects of investment-specific technical change in a model that differentiates between equipment and structures. Related recent work with heterogeneous capital stocks includes Eden and Gaggl (2018) who consider a model with two types of capital and Rognlie (2015) who considers multiple types of productive capital and housing.
} 
small in the sense that it treats the path of the real interest rate as exogenous. ${ }^{34}$

\subsection{Demographics and Growth}

In each period $t$ there is a measure $L_{t}$ of identical workers. Labor-augmenting technology $\tilde{A}_{t}^{L}$ grows at an exogenous rate $g_{t}, \tilde{A}_{t}^{L}=\left(1+g_{t}\right) \tilde{A}_{t-1}^{L}$. In the balanced growth path of the economy the measure of workers and the growth rate of labor-augmenting technology are constant, $L_{t}=L$ and $g_{t}=g$. In what follows, we describe the model directly in terms of variables that are detrended by their respective growth rates in the balanced growth path. Thus, if $\tilde{x}_{t}$ is a variable growing at a rate $g_{x}=\{0, g\}$ along the balanced growth path, the detrended variable $x_{t}$ is defined as $x_{t}=\tilde{x}_{t} /\left(1+g_{x}\right)^{t}$.

\subsection{Final Goods}

The economy produces six final goods. The (non-housing) consumption good is denoted by $C$ and serves as the numeraire good. The consumption of housing services is denoted by $H$. There are four types of investment goods. We denote the $j$ th investment good by $X^{j}$ and, as before, denote the capital stocks by $K^{j}$ for $j=\{I, N, U, H\}$, where $I$ denotes IT capital, $N$ denotes nonIT capital, $U$ denotes unmeasured types of capital such as organizational and intangible capital, and $H$ denotes residential capital. The first three types of capital are used in the production of consumption $C$ and investments $X^{j}$. Residential capital is used in the production of housing services $H$.

Consumption $C_{t}$. Producers of final consumption are perfectly competitive. They operate a CES production function $C_{t}=\left(\int_{0}^{1} c_{t}(z)^{\left(\varepsilon_{t}^{Q}-1\right) / \varepsilon_{t}^{Q}} d z\right)^{\varepsilon_{t}^{Q} /\left(\varepsilon_{t}^{Q}-1\right)}$, where $c_{t}(z)$ denotes the quantity of intermediate business variety $z$ and $\varepsilon_{t}^{Q}>1$ denotes the elasticity of substitution between business varieties. Denoting the price of consumption by $P_{t}^{C}$ and the price of intermediate business variety by $p_{t}^{Q}(z)$, the profit maximization problem yields the demand functions for varieties $c_{t}(z)=\left(p_{t}^{Q}(z) / P_{t}^{C}\right)^{-\varepsilon_{t}^{Q}} C_{t}$. Normalizing $P_{t}^{C}=1$ and anticipating the symmetric

\footnotetext{
${ }^{34}$ We adopt the small open economy assumption with an exogenous real interest rate because it simplifies substantially our inference of the exogenous processes.
} 
equilibrium across all varieties $z$, we obtain $c_{t}(z)=C_{t}$.

Investments $X_{t}^{j}$. Producers of investment good $j=\{I, N, U, H\}$ are similar to the producers of consumption, with the difference being that they operate a CES production function $X_{t}^{j}=$ $\frac{1}{\xi_{t}^{j}}\left(\int_{0}^{1}\left(x_{t}^{j}(z)\right)^{\left(\varepsilon_{t}^{Q}-1\right) / \varepsilon_{t}^{Q}} d z\right)^{\varepsilon_{t}^{Q} /\left(\varepsilon_{t}^{Q}-1\right)}$, where $\xi_{t}^{j}$ denotes the efficiency of producing investment good $j$. The price of investment good $j$ relative to consumption is given by $P_{t}^{j}=\xi_{t}^{j}$. An improvement in the efficiency of producing investment (a lowering of $\xi_{t}^{j}$ ) is associated with a fall in the relative price of investment good $j$. Anticipating the symmetric equilibrium across all varieties $z$, we obtain $x_{t}^{j}(z)=\xi_{t}^{j} X_{t}^{j}$.

Housing services $H_{t}$. Producers of housing services operate a CES production function $H_{t}=\left(\int_{0}^{1} H_{t}^{j}(\zeta)^{\left(\varepsilon_{t}^{H}-1\right) / \varepsilon_{t}^{H}} d \zeta\right)^{\varepsilon_{t}^{H} /\left(\varepsilon_{t}^{H}-1\right)}$, where $H_{t}(\zeta)$ denotes the quantity of intermediate housing variety $\zeta$ and $\varepsilon_{t}^{H}>1$ denotes the elasticity of substitution between housing varieties. Differences in the elasticities of substitution across varieties in the business and the housing sector generate differences in markups across sectors. Denoting the price of housing services by $P_{t}^{H}$ and the price of intermediate housing varieties by $p_{t}^{H}(\zeta)$, the profit maximization problem yields the demand functions for varieties $H_{t}(\zeta)=\left(p_{t}^{H}(\zeta) / P_{t}^{H}\right)^{-\varepsilon_{t}^{H}} H_{t}$. Anticipating the symmetric equilibrium across all varieties $\zeta$, we obtain $H_{t}(\zeta)=H_{t}$ and $p_{t}^{H}(\zeta)=P_{t}^{H}$.

Market clearing. The final consumption good $C_{t}$ is consumed by workers $C_{t}^{L}$, by capitalists $C_{t}^{K}$, and by the rest of the world in the form of net exports $\mathrm{NX}_{t}$. Each investment good $X_{t}^{j}$ is used to augment the respective capital stock $K_{t}^{j}$. The market clearing condition in the business sector is given by $Q_{t}=C_{t}^{L}+C_{t}^{K}+\mathrm{NX}_{t}+\sum_{j} \xi_{t}^{j} X_{t}^{j}$, where $Q_{t}$ denotes business output in units of consumption. Housing services are consumed by workers and capitalists, $H_{t}=H_{t}^{L}+H_{t}^{K}$. Total output in units of consumption equals the sum of business and housing output, $Y_{t}=Q_{t}+P_{t}^{H} H_{t}$.

\subsection{Intermediate Good Producers}

There are two types of intermediate good producers. The business sector produces varieties for consumption $C_{t}$ and investments $X_{t}^{j}$. The housing sector produces varieties for final housing 
services $H_{t}$. The two sectors differ both in their production and in their demand functions.

Business Sector. There is a measure one of differentiated intermediate goods $z$. Business variety $z$ produces output using a CES function of an aggregator of the three capital goods, $k_{t}^{Q}\left(k_{t}^{I}(z), k_{t}^{N}(z), k_{t}^{U}(z)\right)$, and labor $\ell_{t}(z)$ :

$$
q_{t}(z)=\left(\alpha\left(A_{t}^{K} k_{t}^{Q}(z)\right)^{\frac{\sigma-1}{\sigma}}+(1-\alpha)\left(A_{t}^{L} \ell_{t}(z)\right)^{\frac{\sigma-1}{\sigma}}\right)^{\frac{\sigma}{\sigma-1}}
$$

where $\sigma$ denotes the elasticity of substitution between labor and capital, $\alpha$ is a distribution factor, $A_{t}^{K}$ denotes capital-augmenting technology, and $A_{t}^{L}$ denotes labor-augmenting technology. The bundle of capital inputs $k_{t}^{Q}(z)$ is rented at a rate $R_{t}^{Q}$ and labor $\ell(z)$ is rented at a price $W_{t}$.

The producer of variety $z$ sells $q_{t}(z)=c_{t}(z)+\sum_{j} \xi_{t}^{j} x_{t}^{j}(z)$ to final consumption and investment goods producers, internalizing the downward sloping demand function for $q_{t}(z)$. The profitmaximization problem is:

$$
\max _{p_{t}^{Q}(z), q_{t}(z), \ell_{t}(z), k_{t}^{Q}(z)} \pi_{t}^{Q}(z)=p_{t}^{Q}(z) q_{t}(z)-R_{t}^{Q} k_{t}^{Q}(z)-W_{t} \ell_{t}(z),
$$

subject to $q_{t}(z)=\left(p_{t}^{Q}(z)\right)^{-\varepsilon_{t}^{Q}} Q_{t}$ and the production function in equation (8). In the symmetric equilibrium of the model, all varieties have the same production function and make identical choices of inputs and prices. Therefore, for all $z$ we obtain $p_{t}^{Q}(z)=1, q_{t}(z)=Q_{t}, \ell_{t}(z)=L_{t}$, $k_{t}^{Q}(z)=K_{t}^{Q}$, and $\pi_{t}^{Q}(z)=\Pi_{t}^{Q}$. Henceforth, we describe the model in terms of the aggregate variables denoted by capital letters.

The first-order conditions with respect to labor and capital are given by:

$$
\begin{gathered}
(1-\alpha)\left(A_{t}^{L}\right)^{\frac{\sigma-1}{\sigma}}\left(\frac{Q_{t}}{L_{t}}\right)^{\frac{1}{\sigma}}=\mu_{t}^{Q} W_{t}, \\
\alpha\left(A_{t}^{K}\right)^{\frac{\sigma-1}{\sigma}}\left(\frac{Q_{t}}{K_{t}^{Q}}\right)^{\frac{1}{\sigma}}=\mu_{t}^{Q} R_{t}^{Q},
\end{gathered}
$$

where $\mu_{t}^{Q}=\varepsilon_{t}^{Q} /\left(\varepsilon_{t}^{Q}-1\right)$ is the gross markup of price over marginal cost in the business sector. Variations in the elasticity of substitution $\varepsilon_{t}^{Q}$ over time result in (exogenous) changes in $\mu_{t}^{Q}$. Total business income is divided between labor payments, capital payments, and economic profits, $Q_{t}=W_{t} L_{t}+R_{t}^{Q} K_{t}^{Q}+\Pi_{t}^{Q}$. 
Business Capital Aggregator. There is a perfectly competitive intermediary firm that transforms capital types $K_{t}^{I}, K_{t}^{N}$, and $K_{t}^{U}$ into aggregate business capital $K_{t}^{Q}$ with the CES production function:

$$
K_{t}^{Q}=\left(\sum_{j \neq H}\left(\nu_{t}^{j}\right)^{\frac{1}{\theta}}\left(K_{t}^{j}\right)^{\frac{\theta-1}{\theta}}\right)^{\frac{\theta}{\theta-1}},
$$

where $\theta$ denotes the elasticity of substitution between types of capital and $\nu_{t}^{j}$ denotes $j$-specific capital-augmenting technology.

The intermediary firm rents the capital types from the capitalists at prices $R_{t}^{I}, R_{t}^{N}$, and $R_{t}^{U}$ respectively and rents the capital aggregator to the business sector at a rate $R_{t}^{Q}$. From the cost minimization problem we derive the first-order conditions for each type of capital:

$$
K_{t}^{j}=\nu_{t}^{j}\left(\frac{R_{t}^{j}}{R_{t}^{Q}}\right)^{-\theta} K_{t}^{Q},
$$

where the rental rate of business capital is given by:

$$
R_{t}^{Q}=\left(\sum_{j \neq H} \nu_{t}^{j}\left(R_{t}^{j}\right)^{1-\theta}\right)^{\frac{1}{1-\theta}} .
$$

Zero profits in the sector that intermediates capital implies $R_{t}^{Q} K_{t}^{Q}=\sum_{j \neq H} R_{t}^{j} K_{t}^{j}$.

Housing Sector. There is a measure one of differentiated intermediate goods $\zeta$. Housing variety $\zeta$ uses only residential capital $k_{t}^{H}(\zeta)$ in the production process:

$$
h_{t}(\zeta)=A_{t}^{H} k_{t}^{H}(\zeta)
$$

where $A_{t}^{H}$ is the technology in the housing sector. Residential capital is rented from the capitalists at a rental rate $R_{t}^{H}$.

The producer of variety $\zeta$ sells $h_{t}(\zeta)$ to final housing services producers, internalizing the downward sloping demand function for $h_{t}(\zeta)$. The profit-maximization problem is:

$$
\max _{p_{t}^{H}(\zeta), h_{t}(\zeta), k_{t}^{H}(\zeta)} \pi_{t}^{H}(\zeta)=p_{t}^{H}(\zeta) h_{t}(\zeta)-R_{t}^{H} k_{t}^{H}(\zeta)
$$

subject to $h_{t}(\zeta)=\left(p_{t}^{H}(\zeta)\right)^{-\varepsilon_{t}^{H}}\left(P_{t}^{H}\right)^{\varepsilon_{t}^{H}} H_{t}$ and the production function in equation (15). In the symmetric equilibrium of the model, all varieties have the same production function and make 
identical choices of inputs and prices. Therefore, for all $\zeta$ we obtain $p_{t}^{H}(\zeta)=P_{t}^{H}, h_{t}(\zeta)=H_{t}$, $k_{t}^{H}(\zeta)=K_{t}^{H}$ and $\pi_{t}^{H}(\zeta)=\Pi_{t}^{H}$.

From the first-order condition for profit maximization, we obtain the price of housing services relative to consumption:

$$
P_{t}^{H}=\mu_{t}^{H} \frac{R_{t}^{H}}{A_{t}^{H}},
$$

where $\mu_{t}^{H}=\varepsilon_{t}^{H} /\left(\varepsilon_{t}^{H}-1\right)$ is the gross markup of price over marginal cost in the housing sector. Total income generated in the housing sector is divided between capital payments and economic profits, $P_{t}^{H} H_{t}=R_{t}^{H} K_{t}^{H}+\Pi_{t}^{H}$.

\subsection{Households}

The household sector consists of workers who simply consume their labor income and capitalists who choose how much of their capital income to consume, save, and invest.

Workers. There is a measure $L_{t}$ of identical workers who provide labor inelastically and value non-residential consumption $C_{t}^{L}$ and housing services $H_{t}^{L}$ according to a Cobb-Douglas utility function:

$$
\max _{C_{t}^{L}, H_{t}^{L}}\left(C_{t}^{L}\right)^{1-\nu_{t}^{H}}\left(H_{t}^{L}\right)^{\nu_{t}^{H}}
$$

where $\nu_{t}^{H}$ denotes the time-varying preference for housing services. Workers do not have access to capital markets and consume their after-tax-and-transfers labor income. Their budget constraint is given by:

$$
\left(1+\tau_{t}^{c}\right) C_{t}^{L}+P_{t}^{H} H_{t}^{L}=W_{t} L_{t}+T_{t}^{L}
$$

where $\tau_{t}^{c}$ denotes the tax rate on consumption expenditures and $T_{t}^{L}$ denotes transfers from the government.

Workers maximize their utility function (18) subject to the budget constraint (19). Their optimal choice of housing to consumption is given by:

$$
\frac{H_{t}^{L}}{C_{t}^{L}}=\frac{\nu_{t}^{H}}{1-\nu_{t}^{H}} \frac{1+\tau_{t}^{c}}{P_{t}^{H}} .
$$


The government rebates back to workers $T_{t}^{L}=\tau_{t}^{c} C_{t}^{L}$ and, therefore, in equilibrium the total expenditure of workers equals their labor income, $C_{t}^{L}+P_{t}^{H} H_{t}^{L}=W_{t} L_{t} \cdot{ }^{35}$

Capitalists. There is a measure one of identical capitalists who own claims to all firms in the economy and the business and housing capital stocks. They value streams of utility according to:

$$
\max _{C_{t}^{K}, H_{t}^{K},\left\{K_{t+1}^{j}\right\}, D_{t+1}} \sum_{t=0}^{\infty}\left(\prod_{k=0}^{t} \beta_{k}(1+g)^{\frac{1}{\rho}}\right)\left(\frac{1}{1-\frac{1}{\rho}}\right)\left(\left(\left(C_{t}^{K}\right)^{1-\nu_{t}^{H}}\left(H_{t}^{K}\right)^{\nu_{t}^{H}}\right)^{1-\frac{1}{\rho}}-1\right),
$$

where $\rho$ denotes the elasticity of intertemporal substitution and $\beta_{t}$ denotes the time-varying transformed discount factor. Capitalists trade an international bond $D_{t}$ at an exogenous interest rate $r_{t}$. Their budget constraint is given by:

$$
\begin{aligned}
& \left(1+\tau_{t}^{c}\right) C_{t}^{K}+P_{t}^{H} H_{t}^{K}+\left(1+\tau_{t}^{x}\right) \sum_{j} \xi_{t}^{j} X_{t}^{j}+\left(1+\left(1-\tau_{t}^{k}\right) r_{t}\right) D_{t} \\
= & \left(1-\tau_{t}^{k}\right)\left(\sum_{j} R_{t}^{j} K_{t}^{j}+\Pi_{t}^{Q}+\Pi_{t}^{H}\right)+(1+g) D_{t+1}+\tau_{t}^{k} \sum_{j} \delta_{t}^{j} \xi_{t}^{j} K_{t}^{j}+T_{t}^{K} .
\end{aligned}
$$

In the budget constraint, $\tau_{t}^{x}$ denotes the tax rate on investment spending and $\tau_{t}^{k}$ denotes the tax rate on capital income (net of depreciation). The government rebates to capitalists a lump-sum equal to $T_{t}^{K}=\tau_{t}^{c} C_{t}^{K}+\tau_{t}^{x} \sum_{j} \xi_{t}^{j} X_{t}^{j}+\tau_{t}^{k}\left(\sum_{j} R_{t}^{j} K_{t}^{j}+\Pi_{t}^{Q}+\Pi_{t}^{H}-r_{t} D_{t}-\sum_{j} \delta_{t}^{j} \xi_{t}^{j} K_{t}^{j}\right)$. Finally, the stocks of capital evolve according to the law of motion:

$$
(1+g) K_{t+1}^{j}=\left(1-\delta_{t}^{j}\right) K_{t}^{j}+X_{t}^{j}
$$

where $\delta_{t}^{j}$ is the time-varying depreciation rate of the type- $j$ capital stock.

Capitalists maximize their value function (21) subject to the budget constraint (22) and the law of motions for capital (23). Capitalists' optimal choice of housing to non-durable consumption is:

$$
\frac{H_{t}^{K}}{C_{t}^{K}}=\frac{\nu_{t}^{H}}{1-\nu_{t}^{H}} \frac{1+\tau_{t}^{c}}{p_{t}^{H}} .
$$

\footnotetext{
${ }^{35}$ We abstract from labor income taxes because labor is provided inelastically and, to simplify the computation of the model, we rebate to each household the corresponding tax revenues. We model consumption taxes $\tau_{t}^{c}$ because their time-variation affects our inference of the time series of the discount factor $\beta_{t}$ and the relative preference for housing $\nu_{t}^{H}$. Similarly, we model capital $\tau_{t}^{k}$ and investment $\tau_{t}^{x}$ taxes because they affect the rental rate of capital $R_{t}^{j}$ and our inferences of the exogenous processes driving the model.
} 
The first-order conditions with respect to bonds $D_{t+1}$ yields a standard Euler equation:

$$
U^{\prime}\left(C_{t}^{K}\right)=\beta\left(\frac{1+\tau_{t}^{c}}{1+\tau_{t+1}^{c}}\right)\left(1+\left(1-\tau_{t+1}^{k}\right) r_{t+1}\right) U^{\prime}\left(C_{t+1}^{K}\right)
$$

The first-order conditions with respect to the capital stocks $K_{t+1}^{j}$ yield:

$$
\left(1-\tau_{t+1}^{k}\right) R_{t+1}^{j}+\tau_{t+1}^{k} \delta_{t+1}^{j} \xi_{t+1}^{j}+\left(1+\tau_{t+1}^{x}\right) \xi_{t+1}^{j}\left(1-\delta_{t+1}^{j}\right)=\left(1+\tau_{t}^{x}\right) \xi_{t}^{j}\left(1+\left(1-\tau_{t+1}^{k}\right) r_{t+1}\right)
$$

The left-hand side of equation (26) denotes the marginal benefit of purchasing capital in period $t$. This consists of the after-tax rental rate earned in period $t+1$ plus the resale value of undepreciated capital in period $t+1$. The right-hand side of equation (26) is the marginal cost of purchasing capital in period $t$. This equals the foregone gross return capital owners would have earned had they invested resources $\left(1+\tau_{t}^{x}\right) \xi_{t}^{j}$ in the international bond with net return equal to $\left(1-\tau_{t+1}^{k}\right) r_{t+1}$. Lagging by a period and rearranging this equation yields the formula we used in equation (2) to construct the capital shares.

\subsection{Driving Processes}

We describe the exogenous processes in two groups. The first, grouped into the vector $\mathbf{x}_{t}^{O}$, includes exogenous processes that we take directly from the data without solving for the equilibrium of the model. These include the real interest rate $\left\{r_{t}\right\}$, tax rates $\left\{\tau_{t}^{c}, \tau_{t}^{x}, \tau_{t}^{k}\right\}$, labor supply $\left\{L_{t}\right\}$, depreciation rates $\left\{\delta_{t}^{I}, \delta_{t}^{N}, \delta_{t}^{U}, \delta_{t}^{H}\right\}$, relative prices of investment $\left\{\xi_{t}^{I}, \xi_{t}^{N}, \xi_{t}^{U}, \xi_{t}^{H}\right\}$, markups in the business sector $\left\{\mu_{t}^{Q}\right\}$, and markups in the housing sector $\left\{\mu_{t}^{H}\right\}$. ${ }^{36}$ The second, grouped into the vector $\mathbf{x}_{t}^{I}$, includes exogenous processes that we infer so that model-generated variables match their counterparts in the data perfectly as we describe below. These include the discount factor $\left\{\beta_{t}\right\}$, labor-augmenting technology $\left\{A_{t}^{L}\right\}$, capital-augmenting technologies $\left\{A_{t}^{K}\right\}$ and $\left\{\nu_{t}^{I}, \nu_{t}^{N}, \nu_{t}^{U}\right\}$, housing preferences $\left\{\nu_{t}^{H}\right\}$, and housing technology $\left\{A_{t}^{H}\right\}$.

\footnotetext{
${ }^{36}$ The sequences of $r_{t}, \delta_{t}^{U}, \xi_{t}^{U}, \mu_{t}^{Q}$, and $\mu_{t}^{H}$ will in general differ across the three cases described above.
} 


\subsection{Equilibrium}

Households and firms have perfect foresight about the exogenous processes driving the economy. Given these exogenous processes, an equilibrium for this economy is defined as a sequence of prices:

$$
\left\{W_{t}, R_{t}^{Q}, R_{t}^{I}, R_{t}^{N}, R_{t}^{U}, R_{t}^{H}, P_{t}^{H}\right\}
$$

and a sequence of quantities:

$$
\left\{H_{t}^{L}, H_{t}^{K}, H_{t}, C_{t}^{L}, C_{t}^{K}, Q_{t}, K_{t}^{Q}, K_{t}^{I}, K_{t}^{N}, K_{t}^{U}, K_{t}^{H}, X_{t}^{I}, X_{t}^{N}, X_{t}^{U}, X_{t}^{H}, D_{t}\right\}
$$

such that the following conditions hold:

1. The business market clears, $Q_{t}=C_{t}^{L}+C_{t}^{K}+\sum_{j} \xi_{t}^{j} X_{t}^{j}+\left(1+r_{t}\right) D_{t}-(1+g) D_{t+1}$, and the housing market clears, $H_{t}=H_{t}^{L}+H_{t}^{K}$.

2. Firms produce intermediate business varieties with the production function (8), their labor choice satisfies the first-order condition (10), and their capital choice satisfies the first-order condition (11).

3. The allocation of business capital satisfies the three first-order conditions (13) and the aggregate rental rate is given by equation (14).

4. Firms produce intermediate housing services with the production function (15) and their capital choice satisfies the first-order condition (17).

5. Workers' optimal choices satisfy their budget constraint (19) and their first-order condition for housing relative to consumption (20).

6. Capitalists' optimal choices satisfy their budget constraint (22), the four capital accumulation equations (23), their first-order condition for housing relative to consumption (24), their Euler equation (25), and the four equations for the rental rates (26).

The 23 endogenous variables of the model are pinned down from these 24 equations (one equation is redundant by Walras Law). 
Recalling that we have transformed the model in terms of stationary variables, we define a steady state of the transformed model economy as an equilibrium in which all exogenous processes are constant and, as a result, all endogenous variables are constant. ${ }^{37}$ In the balanced growth path, prices $\left\{R_{t}^{Q}, R_{t}^{I}, R_{t}^{N}, R_{t}^{U}, R_{t}^{H}, P_{t}^{H}\right\}$ are constant and the wage and all quantities in equation (28) grow at a constant exogenous growth rate $g$.

\section{Quantitative Results}

In this section we present quantitative results from the model for each of Case $\Pi$, Case $K$, and Case $R$. We begin by describing how we infer the exogenous stochastic processes and by reporting their values. We then present counterfactual experiments in which we shut down some of the exogenous processes to assess their effects on macroeconomic outcomes. Differences across cases reflect both differences in the inferred exogenous processes and differences in the responsiveness of the economy to the dynamics induced by the exogenous processes.

\subsection{Inference}

We assume that the economy reaches a balanced growth path in 2017, the year after our sample ends. ${ }^{38}$ We drop time subscripts to denote variables in the balanced growth path and assume that $r=0.04$. We fix all other exogenous processes and endogenous variables in the balanced growth path at their 2016 values. The only exceptions are the capital stocks. Consistency with the capital accumulation equations and the observed investment flows in 2016 requires setting their balanced growth values to $K^{j}=X^{j} /\left(g+\delta^{j}\right)$.

We assume logarithmic preferences, $\rho=1$, and set the growth rate in the balanced growth path to its sample average of $g=0.033 .{ }^{39}$ We consider two values for the elasticity of substitution between capital and labor in the production function (8), $\sigma=\{1.25,0.75\}$, the first of which

\footnotetext{
${ }^{37} \mathrm{We}$ assume that in the steady state the small open economy faces a real interest rate $r_{t}=\bar{r}_{t}+\psi\left(D_{t}-\bar{D}\right)$, where $\bar{r}_{t}$ is an exogenous interest rate, $\bar{D}$ is a parameter, and $\psi$ is a small but positive parameter that allows to pin down a unique steady state with $r=\left(\frac{1}{1-\tau^{k}}\right)\left(\frac{1}{\beta}-1\right)$ and $D=\bar{D}+\frac{r-\bar{r}}{\psi}$. We assume that $r_{t}$ is exogenous during the transition, with the understanding that $r_{t}$ approximates arbitrarily well $\bar{r}_{t}$ under a sufficiently small $\psi$.

${ }^{38}$ Owing to the small open economy setup, the economy jumps to the balanced growth path once all exogenous variables settle down to a constant value.

${ }^{39}$ As noted before, the growth rates of output are very similar between Case $K$ and the other cases.
} 


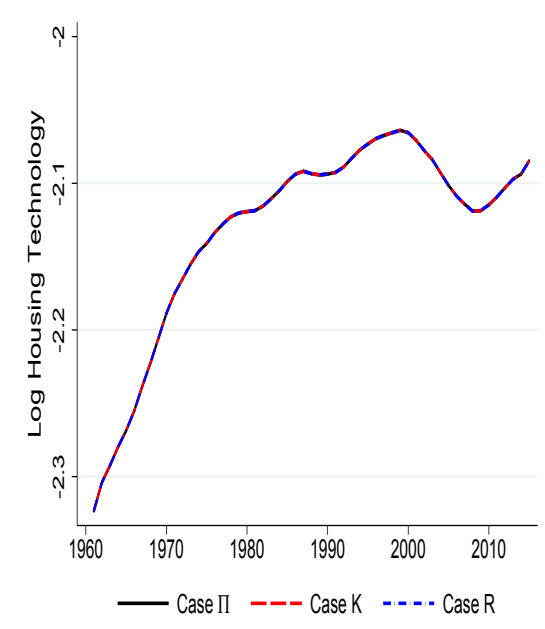

(a) Housing Technology $A_{t}^{H}$

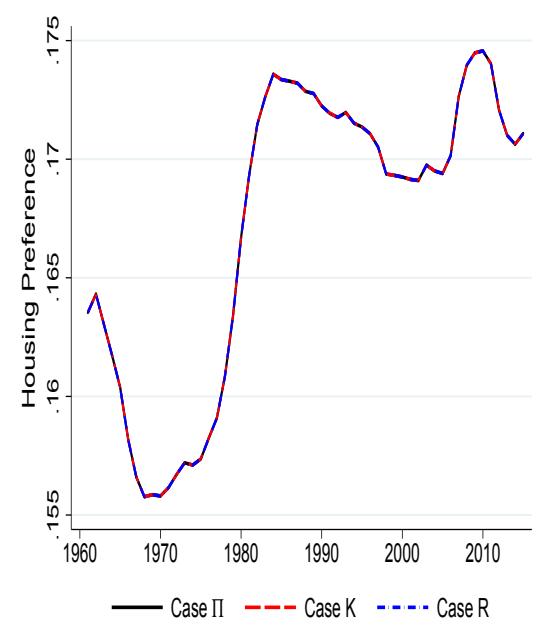

(b) Housing Preference $\nu_{t}^{H}$

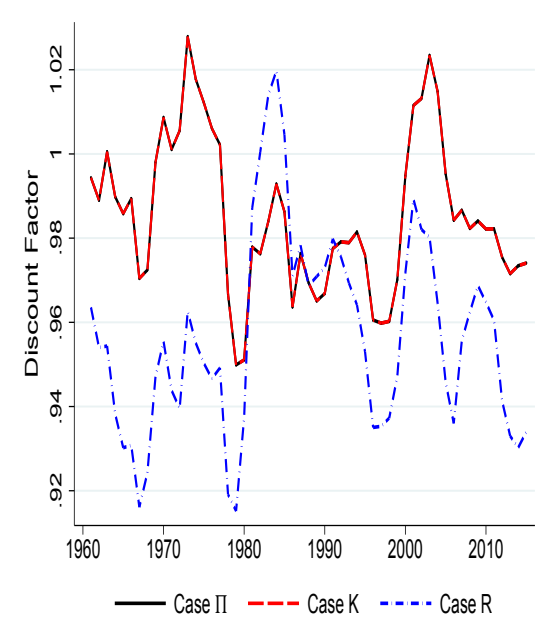

(c) Discount Factor $\beta_{t}$

Figure 11: Housing Technology, Housing Preference, and Discount Factor

is close to estimates in Karabarbounis and Neiman (2014) and the second of which is close to the estimates in Oberfield and Raval (2014) and the values discussed in Chirinko (2008). We normalize the level of labor-augmenting technology in balanced growth to equal the wage, $A^{L}=W$, and choose the distribution factor $\alpha$ in the production function (8) so that the model generates a labor share that equals its data analog in the balanced growth path. We begin our analyses assuming a unitary elasticity $\theta=1$ across capital types in the production function (12) and present sensitivity analyses for different values of $\theta$ in the Appendix.

Given parameter values and observed exogenous processes $\mathbf{x}_{t}^{O}$ taken directly from the data, we infer the values of the exogenous processes $\mathbf{x}_{t}^{I}$ such that the model-generated values of endogenous variables match their analogs in the data. We note that our procedure guarantees that the model perfectly replicates the time series on prices in equation (27) and quantities in equation (28).

In Figure 11 we plot time series of inferred exogenous processes for each of the three cases. Inverting the production function for housing services in equation (15), we calculate $A_{t}^{H}=\frac{H_{t}}{K_{t}^{H}}$. In Figure 11(a), we see that $A_{t}^{H}$ is growing until the 1990s and then remains relatively stable. We calculate the parameter that determines the preference for housing by solving the first-order conditions in equations (20) and (24) for the share $\nu_{t}^{H}=\frac{P_{t}^{H} H_{t}}{P_{t}^{H} H_{t}+\left(1+\tau_{t}^{c}\right) C_{t}}$. Figure 11(b) shows that this share has remained relatively constant at roughly 0.17 over time. 


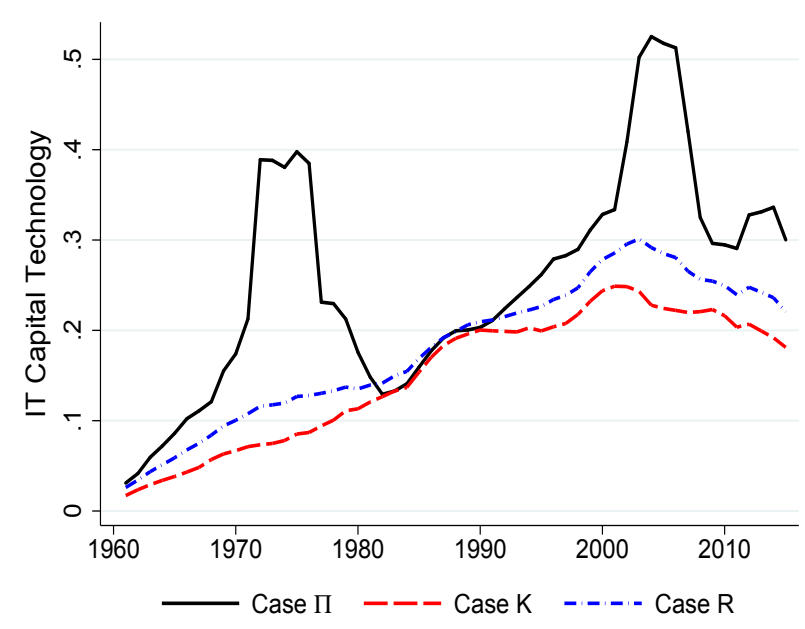

(a) IT Capital Technology $\nu_{t}^{I}$

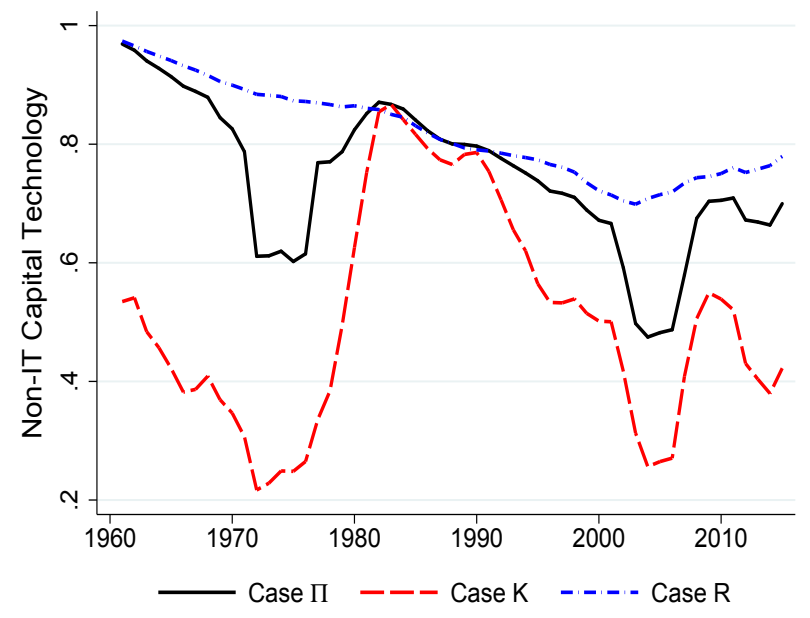

(b) Non-IT Capital Technology $\nu_{t}^{N}$

Figure 12: Capital-Specific Technologies

We infer the path of the discount factor $\beta_{t}$ in Figure 11(c) by inverting the Euler equation for the capitalists (25) and substituting in the values of $r_{t}, \tau_{t}^{c}, P_{t}^{H}, \nu_{t}^{H}$, and $C_{t}^{K}$. We calculate the analog of $C_{t}^{K}$ in the data as the difference between non-housing aggregate consumption $C_{t}$ and the consumption of workers $C_{t}^{L}=\frac{\left(1-\nu_{t}^{H}\right) W_{t} L_{t}}{1+\nu_{t}^{H} \tau_{t}^{c}}$. Given the path of consumption growth for capitalists, we generally obtain a lower value of $\beta_{t}$ under Case $R$ because the $r_{t}$ under this case is generally higher. At annual frequencies, the inferred discount factors generally comove positively across the three cases.

Next, we use the first-order conditions for capital types in equation (13) to infer the capitalspecific technologies $\nu_{t}^{j}$ for $j=\{I, N, U\}$. In Figure 12 we find that $\nu_{t}^{I}$ has grown over time relative to $\nu_{t}^{N}$ in all three cases. This trend reflects the increasing share of IT relative to nonIT capital income over time. To understand the differences across the three cases, recall that Case $R$ uses a revised real interest rate that is generally higher than the real interest rate in Case $\Pi$ and Case $K$. As equation (26) for the rental rate shows, the capital income accruing to IT is less sensitive to $r_{t}$ than the capital income accruing to non-IT because the former has a higher depreciation rate. Therefore, a higher $r_{t}$ increases the share of non-IT capital relative to IT capital and the dashed blue line corresponding to Case $R$ lies below the solid black line corresponding to Case $\Pi$ in Figure 12(a) and the opposite in Figure 12(b). In Case K, part of 


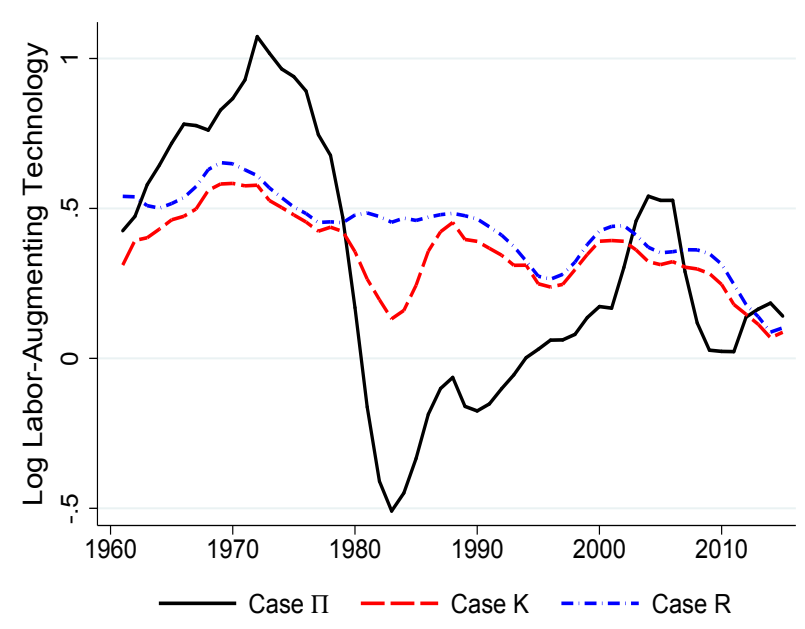

(a) Elasticity of substitution $\sigma=1.25$

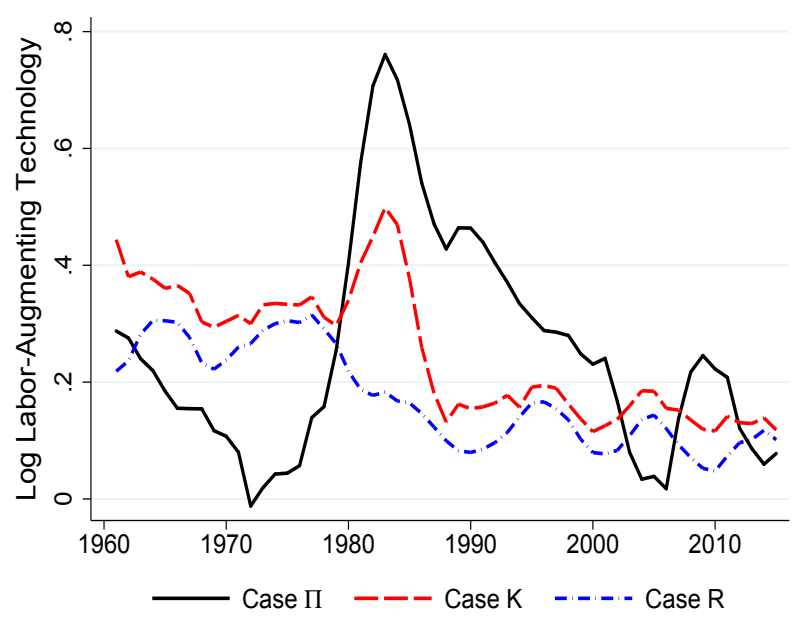

(b) Elasticity of substitution $\sigma=0.75$

Figure 13: Labor-Augmenting Technology $A_{t}^{L}$

capital income is attributed to the unmeasured factor $K_{t}^{U}$. As a result, the share of capital income accruing to both IT and non-IT is smaller and both dashed red lines shift down proportionally by the same factor relative to Case $\Pi$.

Figure 13 presents the inferred time series of $(\log )$ labor-augmenting technology $A_{t}^{L}$ as a function of the elasticity of substitution between capital and labor $\sigma$. To understand how our results depend on which of the three interpretations of factorless income is used, together with the value of $\sigma$, we solve the first-order condition (10) for labor-augmenting technology:

$$
A_{t}^{L}=(1-\alpha)^{\frac{\sigma}{1-\sigma}}\left(s_{L, t}^{Q}\right)^{\frac{1}{\sigma-1}}\left(\mu_{t}^{Q}\right)^{\frac{\sigma}{\sigma-1}} W_{t} .
$$

Labor-augmenting technology $A_{t}^{L}$ in Case $R$, a case featuring constant markups and no unmeasured capital, is plotted with the dot-dashed blue line and is declining over time. As equation (29) illustrates, with an elasticity of $\sigma>1$, the decline in $A_{t}^{L}$ reflects both the decline in $s_{L, t}^{Q}$ and the decline in $W_{t}$ over time. With an elasticity of $\sigma<1$, we still obtain a declining $A_{t}^{L}$ because quantitatively the decline in $W_{t}$ is more important than the decline in $s_{L, t}^{Q}{ }^{40}$ Case $K$ (dashed dotted red line) differs from Case $R$ only because $s_{L, t}^{Q}$ is the labor share of income which now also includes capital income accruing to the unmeasured factor. While there are some

\footnotetext{
${ }^{40}$ Recall that we have detrended all variables that grow in the balanced growth path. So the decline in $A_{t}^{L}$ is relative to a trend of $g=0.033$ per year. We find that $W$ declines by roughly 0.25 log point over the entire sample.
} 


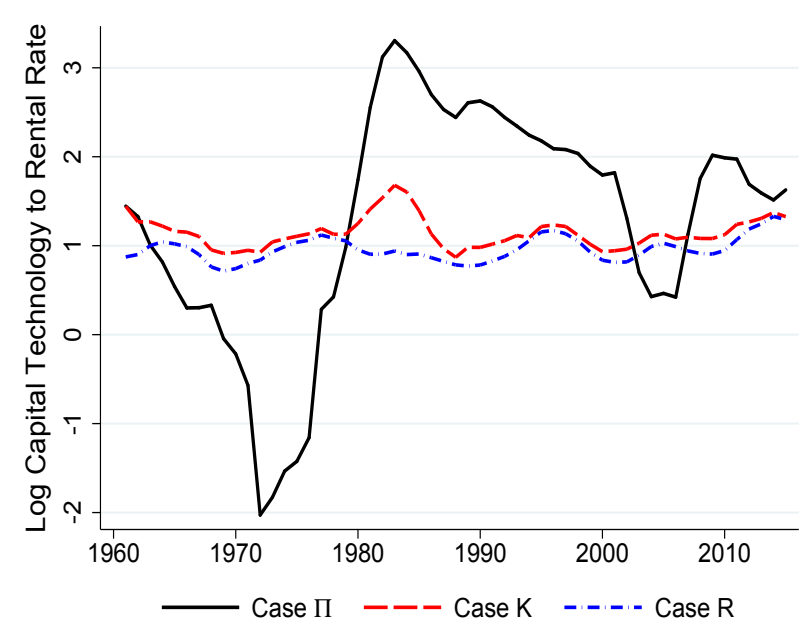

(a) Elasticity of substitution $\sigma=1.25$

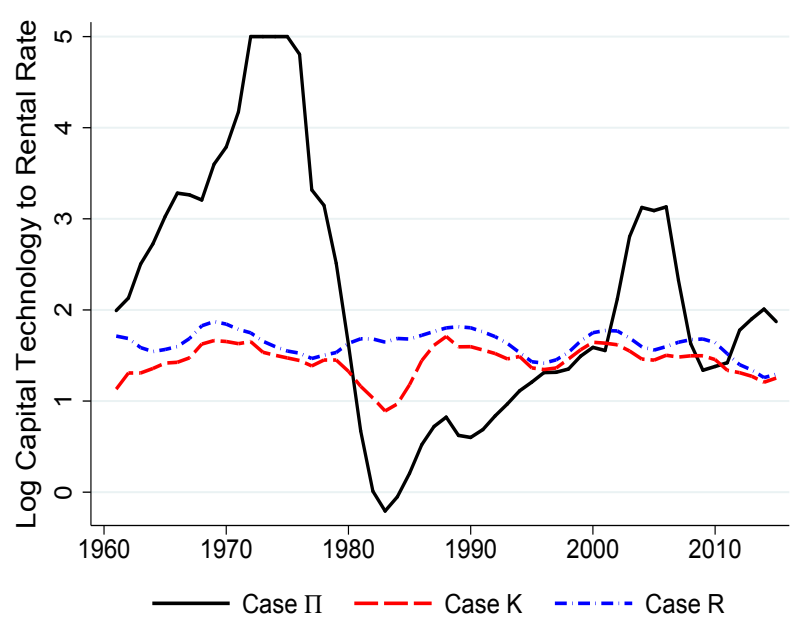

(b) Elasticity of substitution $\sigma=0.75$

Figure 14: Capital-Augmenting Technology to Rental Rate $A_{t}^{K} / R_{t}^{Q}$

differences in the time series of $A_{t}^{L}$ under the two cases (especially around 1980), all time series are declining over time for both values of $\sigma$.

The solid black line shows that $A_{t}^{L}$ is significantly more variable under Case $\Pi$, which allocates factorless income using time-varying markups. Equation (29) shows that with $\sigma>1$, the inferred $A_{t}^{L}$ is positively associated with $\mu_{t}^{Q}$. With $\sigma=1.25$, the decline in markups between the $1970 \mathrm{~s}$ and the early 1980 s leads to a roughly $1.5 \log$ points decline in $A_{t}^{L}$. The increase in markups from the early 1980s is associated with an increase in $A_{t}^{L}$ until roughly the Great Recession. These dynamics of $A_{t}^{L}$ flip when $\sigma=0.75$ because the inferred $A_{t}^{L}$ is negatively associated with $\mu_{t}^{Q}$. We view such large movements in $A_{t}^{L}$ under Case $\Pi$ as implausible.

Finally, Figure 14 presents the inferred time series of (log) capital-augmenting technology relative to the rental rate of business capital, $A_{t}^{K} / R_{t}^{Q}$. To understand why our results differ across the three cases and two values for $\sigma$, consider the first-order condition (11) for capitalaugmenting technology relative to the business rental rate:

$$
\frac{A_{t}^{K}}{R_{t}^{Q}}=\alpha^{\frac{\sigma}{1-\sigma}}\left(s_{K, t}^{Q} \mu_{t}^{Q}\right)^{\frac{1}{\sigma-1}} \mu_{t}^{Q}
$$

where the rental rate in the business sector $R_{t}^{Q}$ is given by equation (14). We present the ratio $A_{t}^{K} / R_{t}^{Q}$ because it is uniquely pinned down from equation (30), irrespective of how one normal- 
izes the capital-specific technologies $\nu_{t}^{j}$ in equation (14) and $A_{t}^{K}$. By contrast, the individual components $A_{t}^{K}$ and $R_{t}^{Q}$ depend on how one normalizes the levels of $\nu_{t}^{j}$ and $A_{t}^{K}{ }^{41}$

The dashed blue line shows that for Case $R, A_{t}^{K} / R_{t}^{Q}$ is increasing over time when $\sigma=1.25$, as shown in Figure 14(a), and is decreasing over time when $\sigma=0.75$, as shown in Figure 14(a). As equation (30) shows, these dynamics reflect the increase in $s_{K, t}^{Q}$ over time under Case R. Case $K$, plotted in the dashed dotted red line, differs from Case $R$ only because $s_{K, t}^{Q}$ is the capital share of income which also includes capital income accruing to the unmeasured factor. While there are some differences in the time series of $A_{t}^{K} / R_{t}^{Q}$ under the two cases (especially around 1980), the broad trends are similar across the two cases.

Similar to our inference of $A_{t}^{L}$, we find that the inferred $A_{t}^{K} / R_{t}^{Q}$ becomes significantly more variable under Case $\Pi$ with time-varying markups as seen in the solid black line. ${ }^{42}$ This reflects the fact that the capital share $s_{K, t}^{Q}$ fluctuates significantly more under Case $\Pi$. By contrast, $s_{K, t}^{Q}$ is more stable either by imputing a revised real interest rate that makes factor shares sum to one in Case $R$ or by attributing the missing income to the unmeasured factor in Case K. Equation (30) shows that with $\sigma>1$, the inferred $A_{t}^{K} / R_{t}^{Q}$ under Case $\Pi$ is positively associated with the capital share of costs, $s_{K, t}^{Q} \mu_{t}^{Q}$ and the markup $\mu_{t}^{Q}$. With $\sigma=1.25$, we obtain a sharp increase in $A_{t}^{K} / R_{t}^{Q}$ between the 1970 s and the early 1980s because the increase in the capital share of costs dominates the decline in the markup. With $\sigma=0.75$ we obtain the opposite patterns. We again view such large movements in $A_{t}^{K}$ relative to $R_{t}^{Q}$ generated by Case $\Pi$ as implausible.

\footnotetext{
${ }^{41}$ With $J$ types of business capital, we have $J$ equations (equations (13) for the $J-1$ relative shares and equation (30) for the first-order condition for capital) to pin down $J+1$ unknowns (the $J$ capital-specific technologies $\nu_{t}^{j}$ and $A_{t}^{K}$ ). This means that we need one more condition that normalizes the $\nu_{t}^{j}$ relative to $A_{t}^{K}$. In our inference, we imposed the normalization $\sum_{j} \nu_{t}^{j}=1$. To see how this normalization matters, denote the equilibrium of the model under our normalizing condition with the superscript 1 and the equilibrium of the model under some alternative normalizing condition with the superscript 2. Suppose that the aggregate rental rates in the two normalizing conditions are related by $\left(R_{t}^{Q}\right)^{2}=x_{t}\left(R_{t}^{Q}\right)^{1}$, where $x_{t}$ is a (potentially) time-varying factor. From equation $(30)$, we see that the ratio $A^{K} / R^{Q}$ does not depend on the normalizing condition, so $\left(A_{t}^{K} / R_{t}^{Q}\right)^{1}=\left(A_{t}^{K} / R_{t}^{Q}\right)^{2}$ and $\left(A_{t}^{K}\right)^{2}=x_{t}\left(A_{t}^{K}\right)^{1}$. Since our inference of exogenous processes guarantees that we match perfectly business capital income $R_{t}^{Q} K_{t}^{Q}$ under any normalizing condition, we obtain that $\left(K_{t}^{Q}\right)^{1}=x_{t}\left(K_{t}^{Q}\right)^{2}$. This implies that $A_{t}^{K} K_{t}^{Q}$ is identical under both normalizing conditions and so are output $Q_{t}$, consumptions $C_{t}^{K}$ and $C_{t}^{L}$, and all other endogenous variables of the model. To summarize, the split of $R_{t}^{Q} K_{t}^{Q}$ and $A_{t}^{K} K_{t}^{Q}$ between $K_{t}^{Q}$ and either $R_{t}^{Q}$ or $A_{t}^{K}$ depends on the particular normalizing condition that a researcher imposes, but all other variables do not.

${ }^{42}$ Case $\Pi$ under an elasticity $\sigma=0.75$ implies explosive values of $\log \left(A_{t}^{K} / R_{t}^{Q}\right)$ during the mid 1970 s. To improve the visual presentation of the results, in Figure 14 we replace such explosive values with a value of 5 .
} 


\subsection{Counterfactuals}

In this section we discuss several counterfactuals and show how our conclusions for the drivers of functional inequality, factor shares, and output depend critically on which case is used to account for factorless income. Our measure of inequality is the consumption of capitalists relative to workers $C_{t}^{K} / C_{t}^{L}{ }^{43}$ While admittedly stark, in our model $C_{t}^{K} / C_{t}^{L}$ reflects the between income groups consumption inequality as workers earn all labor income and capitalists earn all capital income in the economy.

To understand the drivers of relative consumption $C_{t}^{K} / C_{t}^{L}$, we express it as a function of relative incomes net of depreciation across the two types of households, the investment behavior of capitalists, and the saving behavior of capitalists. We define the share of business depreciation in business output as $\psi_{t}^{Q}=\frac{\sum_{j \neq H} \delta_{t}^{j} \xi_{t}^{j} K_{t}^{j}}{Q_{t}}$ and the share of net business output in total net income as $\phi_{t}^{Q}=\frac{Q_{t}-\sum_{j \neq H} \delta_{t}^{j} \xi_{t}^{j} K_{t}^{j}}{Y_{t}-\sum_{j} \delta_{t}^{j} \xi_{t}^{j} K_{t}^{j}}$. Using the budget constraints of the capitalists and the workers, we arrive at the expression:

$$
\frac{C_{t}^{K}}{C_{t}^{L}}=\frac{1-\psi_{t}^{Q}}{s_{L, t}^{Q} \phi_{t}^{Q}}\left[1-\frac{s_{L, t}^{Q} \phi_{t}^{Q}}{1-\psi_{t}^{Q}}-\frac{\sum_{j} \xi_{t}^{j}\left(X_{t}^{j}-\delta_{t}^{j} K_{t}^{j}\right)}{Y_{t}-\sum_{j} \delta_{t}^{j} \xi_{t}^{j} K_{t}^{j}}-\frac{\left(1+r_{t}\right) D_{t}-(1+g) D_{t+1}}{Y_{t}-\sum_{j} \delta_{t}^{j} \xi_{t}^{j} K_{t}^{j}}\right] .
$$

A body of work since at least Weitzman (1976) has argued that the net concept of the labor share may be more closely associated with welfare and inequality than their gross counterparts because, unlike the rest of gross income, depreciation cannot be consumed by households. This logic appears in equation (31), which shows that relative consumption of capitalists in decreasing in the net labor share of total income $\frac{s_{L, t}^{Q} \phi_{t}^{Q}}{1-\psi_{t}^{Q}}$. However, this equation shows that there are additional factors that influence inequality. Investment motives affect relative consumption through the third term in the brackets, with relative consumption decreasing in the net investment rate of capitalists $\frac{\sum_{j} \xi_{t}^{j}\left(X_{t}^{j}-\delta_{t}^{j} K_{t}^{j}\right)}{Y_{t}-\sum_{j} \delta_{t}^{j} \xi_{t}^{j} K_{t}^{j}}$. Saving motives affect relative consumption through the last term in

\footnotetext{
${ }^{43}$ With identical log preferences over a Cobb-Douglas bundle, the ratio of consumption completely characterizes welfare differences across the two types of households in a balanced growth path. We do not present welfare-based measures of inequality during the transition because these depend on ad-hoc assumptions about when the economy reaches a balanced growth path. We also wish to acknowledge that our results for inequality depend crucially on the assumption that capitalists are infinitely-lived and have perfect foresight. In this case $C_{t}^{K}$ depends on the aftertax return on bonds (the substitution effect) and terminal consumption (the wealth effect) as seen from the Euler equation (25).
} 
the brackets. Relative consumption decreases when capitalists decrease their stock of debt and the term $\frac{\left(1+r_{t}\right) D_{t}-(1+g) D_{t+1}}{Y_{t}-\sum_{j} \delta_{t}^{j} \xi_{t}^{j} K_{t}^{j}}$ is positive. ${ }^{44}$

We organize our discussion of the counterfactuals for relative consumption $\log \left(C^{K} / C^{L}\right)$ in Table 2, for the business labor share $s_{L}^{Q}$ in Table 3, and for business output $\log Q$ in Table 4 . Each table is split in two panels. The top panel represents changes in these variables between the beginning of the sample (represented by the average value of each variable between 1961 and 1965) and the end of the sample (represented by the average value of each variable between 2011 and 2015). The bottom panel represents changes of these variables between the middle of the panel (averages between 1986 and 1990) and the end of the sample. The columns of the table present Case $\Pi$, Case $K$, and Case $R$ under the two different values of the elasticity of substitution between capital and labor $\sigma$.

The top row of each table, labeled "Baseline," shows changes which, by construction, match the changes of the corresponding variables in the data perfectly. For example, Table 2 shows that from the beginning to the end of the sample $C^{K} / C^{L}$ increased by $0.427 \log$ point. The other rows display counterfactuals in which we shut down particular exogenous processes that drive the transitional dynamics of the model. The entries in each counterfactual show the change in the baseline minus the change in each counterfactual. A positive entry means that the exogenous process causes a particular variable to increase. For example, row 1 in the upper panel of Table 2 shows that under Case $\Pi$ and $\sigma=1.25$, markups led to a $0.009 \log$ point decrease in $C^{K} / C^{L}$.

The first counterfactual we consider is setting the markup $\mu_{t}^{Q}$ to its average value in each of the three cases over the entire sample period. We illustrate the evolution of $\log \left(C_{t}^{K} / C_{t}^{L}\right)$ in Figure 15 for $\sigma=1.25$ and $\sigma=0.75$. The solid black lines in Figure 15 are labeled "Baseline" and correspond to the roughly $0.4 \log$ point increase in $\log \left(C_{t}^{K} / C_{t}^{L}\right)$ found in the data and perfectly reproduced by the model when all exogenous processes are active. Since markups are constant

\footnotetext{
${ }^{44}$ In a balanced growth path with $g>0$ the third term in the brackets becomes $\frac{g \sum_{j} \xi^{j} K^{j}}{Y-\sum_{j} \delta^{j} \xi^{j} K^{j}}$ and is positive because capitalists have to finance the growing capital of the economy. When $r>g$ and $D>0$, the fourth term in the brackets becomes $\frac{(r-g) D}{Y-\sum_{j} \delta^{j} \xi^{j} K^{j}}$ and is positive because capitalists have to finance growing interest payments on their debt.
} 
Table 2: Counterfactuals: Relative Consumption $\log \left(C^{K} / C^{L}\right)$

\begin{tabular}{l|ccc|ccc}
\hline \hline & \multicolumn{3}{|c|}{ Elasticity $\sigma=1.25$} & \multicolumn{3}{c}{ Elasticity $\sigma=0.75$} \\
\hline & Case $\Pi$ & Case $K$ & Case $R$ & Case $\Pi$ & Case $K$ & Case $R$ \\
\hline Baseline & 0.427 & 0.427 & 0.427 & 0.427 & 0.427 & 0.427 \\
1. $\mu^{Q}$ & -0.009 & 0.002 & 0.000 & -0.009 & 0.002 & 0.000 \\
2. $r$ & -0.350 & -0.319 & 1.021 & -0.353 & -0.319 & 1.042 \\
3. $A^{L}$ & 0.415 & 0.289 & 0.370 & 0.154 & 0.259 & 0.180 \\
4. $\xi^{I}$ & -0.142 & -0.146 & -0.172 & -0.172 & -0.166 & -0.202 \\
5. $\left(A^{K}, \nu^{I}\right)$ & -0.386 & -0.643 & -0.309 & -0.215 & -1.005 & -0.206 \\
6. $\xi^{N}$ & 0.036 & 0.035 & 0.094 & 0.032 & 0.033 & 0.083 \\
7. $\left(A^{K}, \nu^{N}\right)$ & -0.093 & -0.752 & -0.110 & 0.165 & -0.645 & 0.078 \\
8. $L$ & -0.183 & -0.183 & -0.183 & -0.183 & -0.183 & -0.183 \\
9. $\tau^{k}$ & 0.103 & 0.079 & 0.156 & 0.103 & 0.081 & 0.156 \\
\hline & 0.019615 and $2011-2015$ \\
\hline Baseline & 0.335 & 0.335 & 0.335 & 0.335 & 0.335 & 0.335 \\
1. $\mu^{Q}$ & 0.151 & 0.000 & 0.000 & 0.152 & 0.000 & 0.000 \\
2. $r$ & -0.240 & -0.327 & 0.527 & -0.242 & -0.320 & 0.517 \\
3. $A^{L}$ & -0.228 & 0.340 & 0.345 & 0.342 & 0.003 & -0.002 \\
4. $\xi^{I}$ & -0.094 & -0.098 & -0.124 & -0.122 & -0.116 & -0.152 \\
5. $\left(A^{K}, \nu^{I}\right)$ & 0.216 & -0.313 & -0.276 & -0.402 & -0.214 & 0.011 \\
6. $\xi^{N}$ & -0.009 & -0.009 & 0.057 & -0.009 & -0.008 & 0.049 \\
7. $\left(A^{K}, \nu^{N}\right)$ & 0.433 & 0.033 & -0.202 & -0.132 & 0.615 & 0.141 \\
8. $L$ & 0.019 & 0.019 & 0.019 & 0.019 & 0.019 & 0.019 \\
9. $\tau^{k}$ & 0.055 & -0.016 & 0.115 & 0.055 & -0.008 & 0.115 \\
\hline \hline
\end{tabular}

The table summarizes the counterfactual changes for relative consumption $\log \left(C^{K} / C^{L}\right)$. The rows labeled "Baseline" shows changes between 1961-1965 and 2011-2015 (upper panel) and 1986-1990 and 2011-2015 (lower panel) in the baseline model which, by construction, match the changes of $\log \left(C^{K} / C^{L}\right)$ in the data perfectly. Positive entries denote an increase in $\log \left(C^{K} / C^{L}\right)$. The entries in rows 1 to 9 denote differences relative to the baseline. The differences are calculated as the change in the baseline minus the change in each counterfactual. A positive entry in rows 1 to 9 means that the exogenous process causes $\log \left(C^{K} / C^{L}\right)$ to increase. 
Table 3: Counterfactuals: Business Labor Share $s_{L}^{Q}$

\begin{tabular}{l|ccc|ccc}
\hline \hline & \multicolumn{3}{|c|}{ Elasticity $\sigma=1.25$} & \multicolumn{3}{c}{ Elasticity $\sigma=0.75$} \\
\hline & Case $\Pi$ & Case $K$ & Case $R$ & Case $\Pi$ & Case $K$ & Case $R$ \\
\hline \multirow{3}{*}{ Baseline } & -0.016 & -0.003 & -0.016 & -0.016 & -0.003 & -0.016 \\
1. $\mu^{Q}$ & 0.007 & -0.001 & 0.000 & 0.007 & -0.001 & 0.000 \\
2. $r$ & -0.005 & 0.000 & -0.014 & 0.005 & 0.000 & 0.011 \\
3. $A^{L}$ & 0.000 & 0.000 & 0.000 & 0.000 & 0.000 & 0.000 \\
4. $\xi^{I}$ & -0.024 & -0.025 & -0.029 & 0.028 & 0.027 & 0.033 \\
5. $\left(A^{K}, \nu^{I}\right)$ & -0.064 & -0.114 & -0.055 & 0.032 & 0.154 & 0.033 \\
6. $\xi^{N}$ & 0.006 & 0.006 & 0.015 & -0.005 & -0.006 & -0.014 \\
7. $\left(A^{K}, \nu^{N}\right)$ & -0.015 & -0.123 & -0.019 & -0.027 & 0.109 & -0.013 \\
8. $L$ & 0.000 & 0.000 & 0.000 & 0.000 & 0.000 & 0.000 \\
9. $\tau^{k}$ & 0.001 & -0.003 & 0.000 & -0.001 & 0.003 & 0.000 \\
\hline & -3 & Changes between $1986-1990$ and $2011-2015$ \\
\hline Baseline & -0.030 & -0.029 & -0.030 & -0.030 & -0.029 & -0.030 \\
1. $\mu^{Q}$ & -0.071 & 0.000 & 0.000 & -0.083 & 0.000 & 0.000 \\
2. $r$ & -0.015 & -0.030 & 0.012 & 0.016 & 0.029 & -0.011 \\
3. $A^{L}$ & 0.000 & 0.000 & 0.000 & 0.000 & 0.000 & 0.000 \\
4. $\xi^{I}$ & -0.016 & -0.016 & -0.021 & 0.019 & 0.018 & 0.024 \\
5. $\left(A^{K}, \nu^{I}\right)$ & 0.041 & -0.056 & -0.048 & 0.063 & 0.025 & -0.003 \\
6. $\xi^{N}$ & -0.002 & -0.002 & 0.009 & 0.002 & 0.002 & -0.008 \\
7. $\left(A^{K}, \nu^{N}\right)$ & 0.075 & 0.009 & -0.035 & 0.023 & -0.094 & -0.024 \\
8. $L$ & 0.000 & 0.000 & 0.000 & 0.000 & 0.000 & 0.000 \\
9. $\tau^{k}$ & 0.000 & -0.012 & 0.002 & 0.000 & 0.011 & -0.001 \\
\hline \hline
\end{tabular}

The table summarizes the counterfactual changes for the business labor share $s_{L}^{Q}$. The rows labeled "Baseline" shows changes between 1961-1965 and 2011-2015 (upper panel) and 1986-1990 and 2011-2015 (lower panel) in the baseline model which, by construction, match the changes of $s_{L}^{Q}$ in the data perfectly. Negative entries denote a decrease in $s_{L}^{Q}$. The entries in rows 1 to 9 denote differences relative to the baseline. The differences are calculated as the change in the baseline minus the change in each counterfactual. A negative entry rows 1 to 9 means that the exogenous process causes $s_{L}^{Q}$ to decrease. 
Table 4: Counterfactuals: Output $\log Q$

\begin{tabular}{|c|c|c|c|c|c|c|}
\hline & \multicolumn{3}{|c|}{ Elasticity $\sigma=1.25$} & \multicolumn{3}{|c|}{ Elasticity $\sigma=0.75$} \\
\hline & Case $\Pi$ & Case $K$ & Case $R$ & Case $\Pi$ & Case $K$ & Case $R$ \\
\hline & \multicolumn{6}{|c|}{ Changes between 1961-1965 and 2011-2015 } \\
\hline Baseline & -0.068 & -0.087 & -0.068 & -0.068 & -0.087 & -0.068 \\
\hline 1. $\mu^{Q}$ & 0.000 & -0.001 & 0.000 & 0.000 & 0.000 & 0.000 \\
\hline 2. $r$ & 0.038 & -0.001 & 0.103 & 0.025 & 0.000 & 0.045 \\
\hline 3. $A^{L}$ & -0.415 & -0.289 & -0.370 & -0.154 & -0.259 & -0.180 \\
\hline 4. $\xi^{I}$ & 0.177 & 0.183 & 0.215 & 0.129 & 0.125 & 0.151 \\
\hline 5. $\left(A^{K}, \nu^{I}\right)$ & 0.482 & 0.804 & 0.386 & 0.161 & 0.754 & 0.154 \\
\hline $6 . \xi^{N}$ & -0.045 & -0.044 & -0.117 & -0.024 & -0.025 & -0.062 \\
\hline 7. $\left(A^{K}, \nu^{N}\right)$ & 0.116 & 0.940 & 0.138 & -0.124 & 0.483 & -0.058 \\
\hline 8. $L$ & 0.183 & 0.183 & 0.183 & 0.183 & 0.183 & 0.183 \\
\hline \multirow[t]{2}{*}{ 9. $\tau^{k}$} & -0.005 & 0.025 & -0.001 & -0.003 & 0.014 & -0.001 \\
\hline & \multicolumn{6}{|c|}{ Changes between 1986-1990 and 2011-2015 } \\
\hline Baseline & -0.147 & -0.148 & -0.147 & -0.147 & -0.148 & -0.147 \\
\hline 1. $\mu^{Q}$ & -0.046 & 0.000 & 0.000 & -0.028 & 0.000 & 0.000 \\
\hline 2. $r$ & 0.113 & 0.221 & -0.094 & 0.069 & 0.128 & -0.048 \\
\hline 3. $A^{L}$ & 0.228 & -0.340 & -0.345 & -0.342 & -0.003 & 0.002 \\
\hline 4. $\xi^{I}$ & 0.118 & 0.123 & 0.155 & 0.091 & 0.087 & 0.114 \\
\hline 5. $\left(A^{K}, \nu^{I}\right)$ & -0.270 & 0.391 & 0.345 & 0.302 & 0.160 & -0.008 \\
\hline 6. $\xi^{N}$ & 0.011 & 0.012 & -0.071 & 0.006 & 0.006 & -0.037 \\
\hline 7. $\left(A^{K}, \nu^{N}\right)$ & -0.541 & -0.041 & 0.252 & 0.099 & -0.461 & -0.106 \\
\hline 8. $L$ & -0.019 & -0.019 & -0.019 & -0.019 & -0.019 & -0.019 \\
\hline 9. $\tau^{k}$ & -0.003 & 0.086 & -0.013 & -0.001 & 0.045 & -0.007 \\
\hline
\end{tabular}

The table summarizes the counterfactual changes for output $\log Q$. The rows labeled "Baseline" shows changes between 1961-1965 and 2011-2015 (upper panel) and 1986-1990 and 2011-2015 (lower panel) in the baseline model which, by construction, match the changes of $\log Q$ in the data perfectly. Negative entries denote a decrease in $\log Q$ relative to a trend of $g=0.033$. The entries in rows 1 to 9 denote differences relative to the baseline. The differences are calculated as the change in the baseline minus the change in each counterfactual. A negative entry in rows 1 to 9 means that the exogenous process causes $\log Q$ to decrease. 


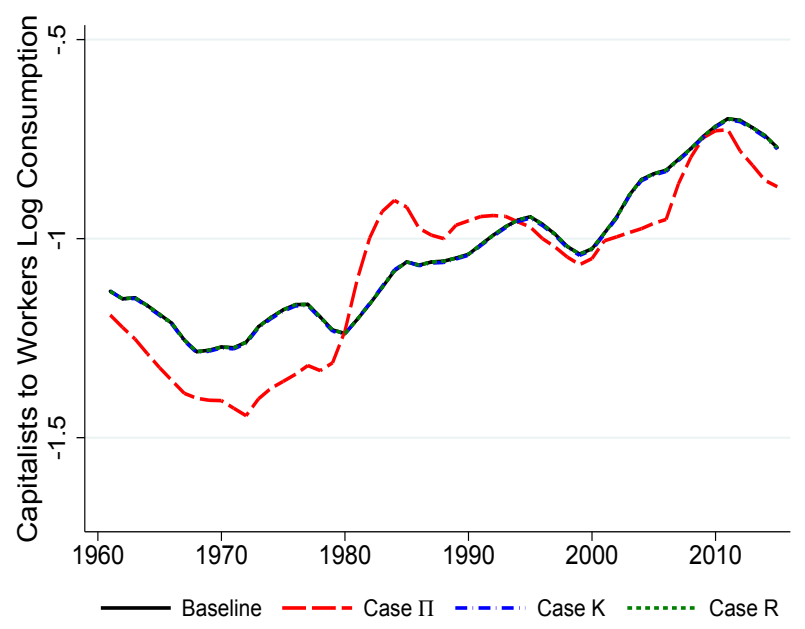

(a) $\sigma=1.25$

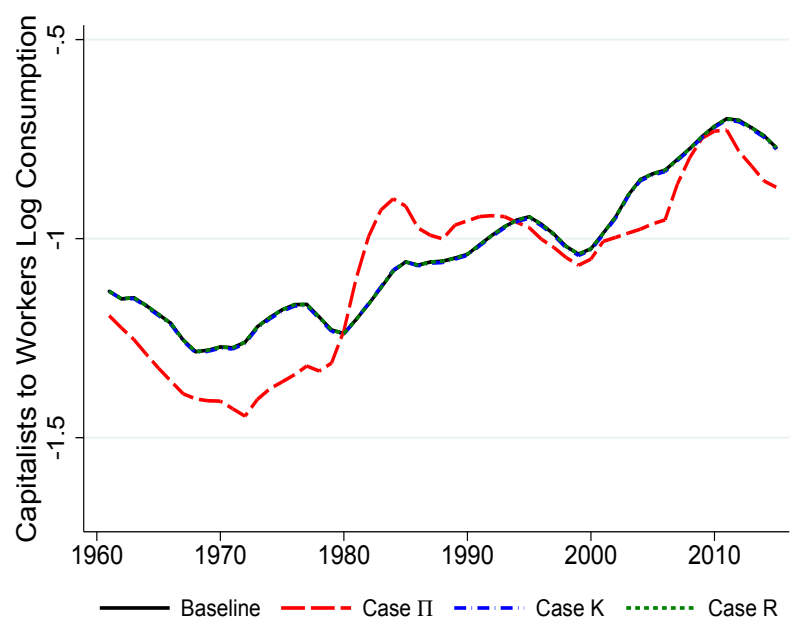

(b) $\sigma=0.75$

Figure 15: Relative Consumption and Markups

in Case $R$ and almost constant in Case $K$, counterfactuals that eliminate markup variation in those cases do not affect endogenous variables. The lines corresponding to those cases, therefore, are visually indistinguishable from the baseline. ${ }^{45}$

The dashed red lines in Figure 15 show that eliminating the inferred markups from Case $\Pi$ over the full sample period makes little difference for the trend in inequality, since the dashed red line starts and ends at a similar distance below the solid black line. We find that this conclusion is robust to the value of $\sigma$. Though markups have not significantly impacted the trajectory of relative consumption from 1960 to 2015, the dashed red lines rise more steeply than the baseline during the first half of the sample and are flatter since the early 1980s. So, under Case $\Pi$, the interpretation is that the declining markups in the first half of our sample decreased the relative consumption of capitalists while the increasing markups in the second half restored it to near its initial value.

Eliminating the variation in markups results in movements in the business labor share in the opposite direction as the movements in inequality. This is expected from equation (31) which shows that, holding constant everything else, a lower $s_{L}^{Q}$ increases $C^{K} / C^{L}$. Table 3 shows that markups are associated with a 0.7 percentage point increase in the labor share since the beginning

\footnotetext{
${ }^{45}$ The small effects under Case $K$ are explained by the fact that in the baseline of Case $K$ we have set the profit share a constant fraction of measured business output $Q-\xi^{U} X^{U}$ rather than business output $Q$.
} 


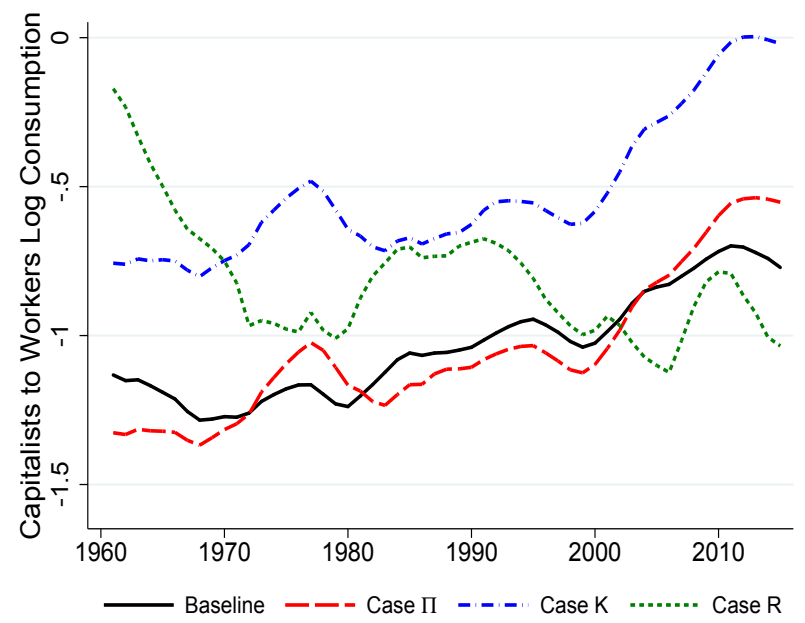

(a) $\sigma=1.25$

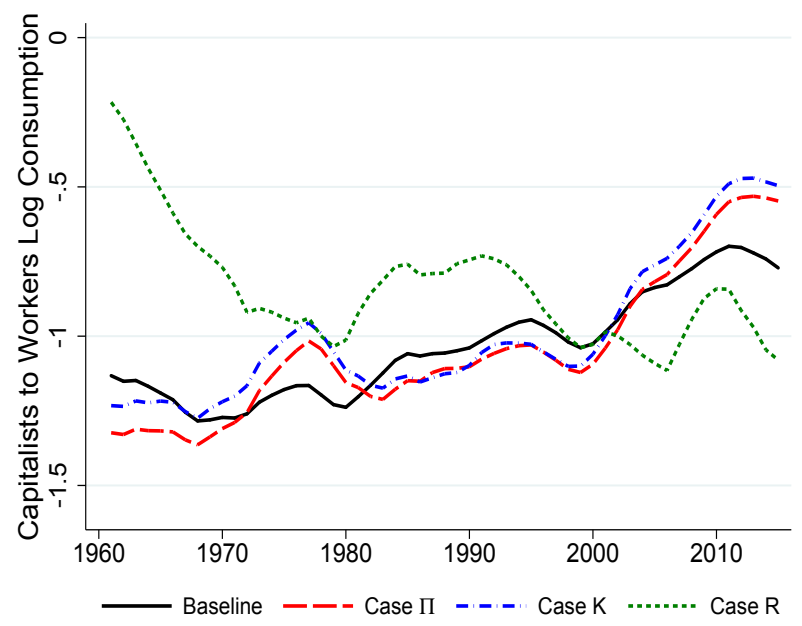

(b) $\sigma=0.75$

Figure 16: Relative Consumption and Real Interest Rate

of the sample in 1960. Barkai (2016) and Eggertsson, Robbins, and Wold (2018), by contrast, emphasize the increase of markups for the labor share decline. The difference in our conclusions stems from the different starting points of our samples, as shown in Figure 2(a). Similar to these authors who begin their analysis in the 1980s, we find that the increase in markups leads to a decline in the labor share of roughly 7 to 8 percentage points between 1986-1990 and 2011-2015 depending on the elasticity of substitution. ${ }^{46}$ We also find declines in business output in these counterfactuals of roughly 0.03 to 0.05 log point during that period.

Next, we set the real interest rate equal to its value in the balanced growth path in all periods beginning in 1960, $r=0.04$. Choosing the same level of $r$ in all three cases guarantees that our results are not driven by differences in the long-run level of capitalists' consumption across the three cases. The short-dashed green lines in Figure 16 correspond to counterfactuals where $r=0.04$ but where all other exogenous driving processes are preserved at their inferred values under Case $R$. Unlike the baseline case which features an increase in inequality, these short-dashed green lines reveal a decline of inequality over time by nearly a log point. The high level of $r$ in Case $R$ leads to an increase in $C^{K} / C^{L}$ because capitalists save more to finance a

\footnotetext{
${ }^{46}$ Barkai (2016) starts his sample in 1984. Eggertsson, Robbins, and Wold (2018) show markup series starting in 1980 in all their analyses with the exception of Figure A.4 that starts in 1970. Consistent with our analysis, their Figure A.4 shows that the profit share has a similar level in 1970 and 2010.
} 


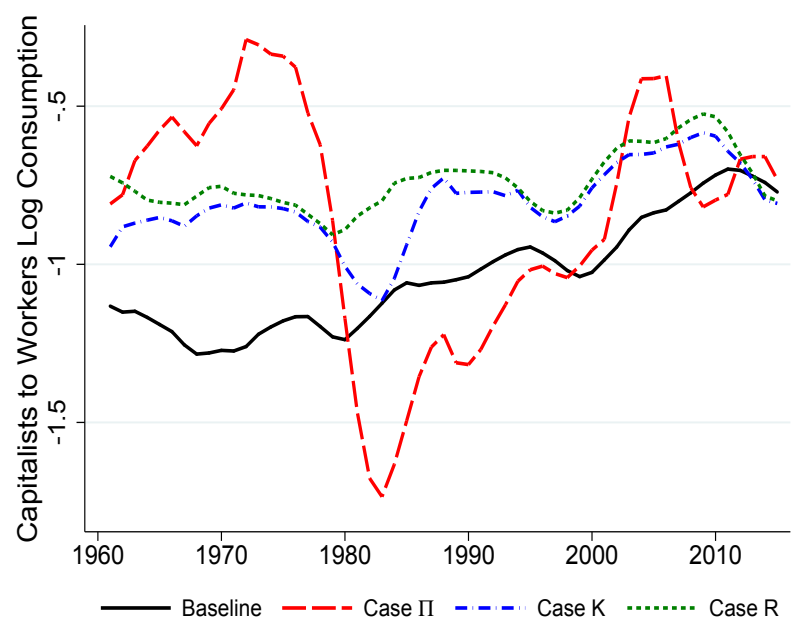

(a) $\sigma=1.25$

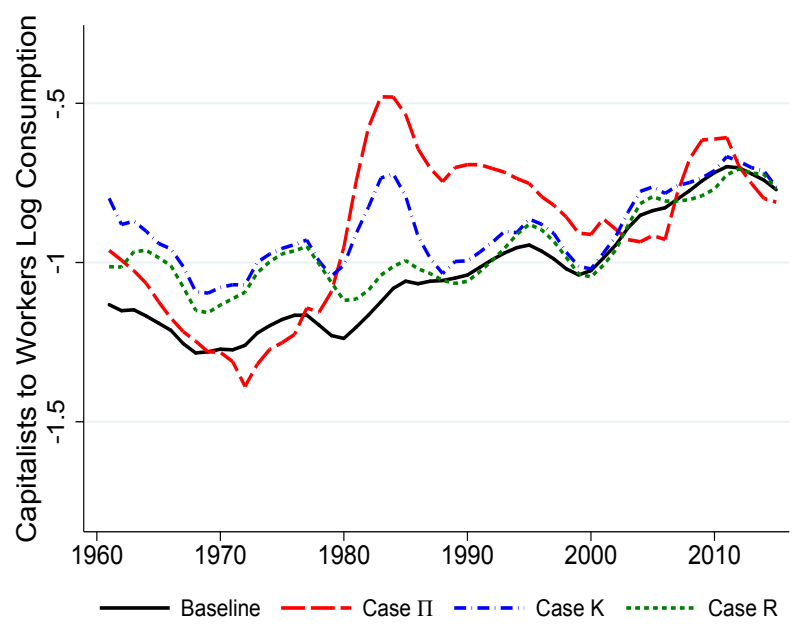

(b) $\sigma=0.75$

Figure 17: Relative Consumption and Labor-Augmenting Technology

growing consumption and this pushes down the last term of equation (31). Case $\Pi$ and Case $K$ feature lower and more declining values for $r$, so counterfactuals which remove that variation cause the lines corresponding to those cases to increase relative to the baseline case. We conclude, therefore, that the cost of capital is quantitatively significant for accounting for the increase in relative consumption under Case $R$ but not under Case $\Pi$ and Case $K$.

The impact of $r$ on $s_{L}^{Q}$ and $Q$ is intermediated by changes in the business sector rental rate of capital $R^{Q}$. Given constant markups, equation (30) shows that a decline in $r$ leads to a decline in $s_{L}^{Q}$ when $\sigma>1$ and $R^{Q}$ declines, whereas it leads to an increase in $s_{L}^{Q}$ if $\sigma<1$ and $R^{Q}$ increases or the reverse. ${ }^{47}$ We also find that the lower $r$ in the baseline compared to the counterfactual increases $Q$ in most cases, as capitalists substitute from consumption toward capital accumulation. An important exception is the period between the end of 1980s and the 2010s under Case $R$, in which the high baseline levels of $r$ compared to the counterfactual lead to a decline in $Q$.

In Figure 17 we plot the relative consumption path under the counterfactual that laboraugmenting technology $A^{L}$ always equals its value in the first period of our sample. In all cases

\footnotetext{
${ }^{47}$ Compositional changes across types of capital imply that the rental rate $R^{Q}$ is differentially sensitive to changes in $r$ across the three cases. In most cases, we find that $r$ leads to a decline in $s_{L}^{Q}$ when $\sigma>1$, although the effects differ significantly across sample periods and cases.
} 


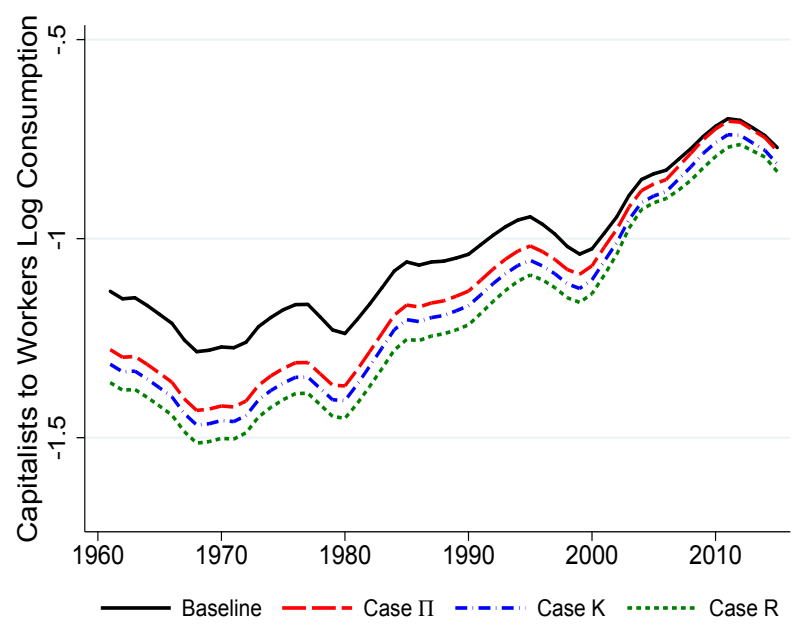

(a) $\sigma=1.25$

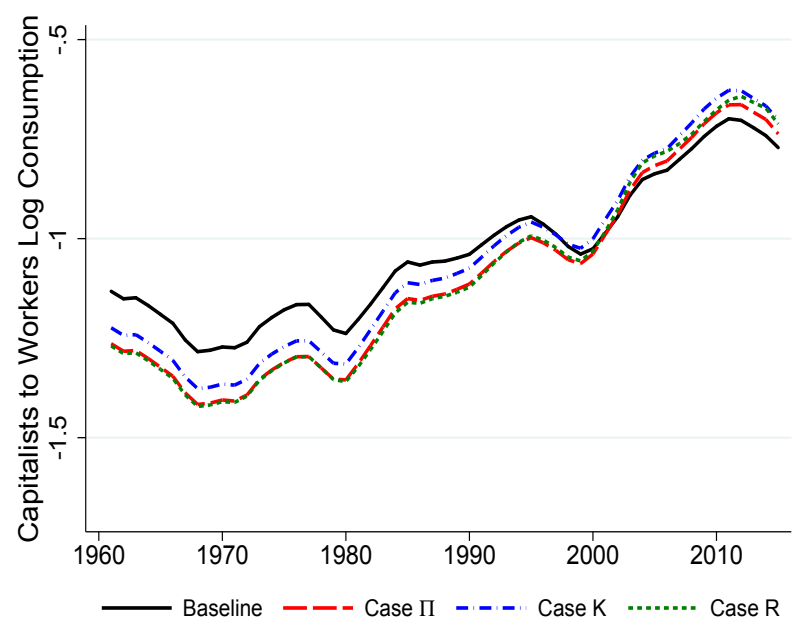

(b) $\sigma=0.75$

Figure 18: Relative Consumption and IT Prices

and for both elasticities, the lines exhibit either a decline or a more muted increase than the baseline case over the full sample. With $\sigma=1.25, A^{L}$ accounts for nearly all of the increase in $C^{K} / C^{L}$ from the 1960s under Case $\Pi$ and for roughly 85 and 70 percent of the increase under Case $K$ and Case $R$ respectively. With $\sigma=0.75, A^{L}$ accounts between roughly 35 and 60 percent of the increase in $C^{K} / C^{L}{ }^{48}$ We conclude that the decline in $A^{L}$ since the 1960 s can be robustly linked to an increase in $C^{K} / C^{L}$. The key force leading to the increased inequality is the decline in the investment rate of the capitalists as shown in the third term of equation (31). As shown in Table 3, labor-augmenting technology $A^{L}$ has no effect on the business labor share $s_{L}^{Q}$. Table 4 shows that the negative effects of $A^{L}$ on output $Q$ are larger in the higher substitution economy with $\sigma=1.25$ than in the lower substitution economy with $\sigma=0.75$.

Finally, Figure 18 shows the relative consumption path when we remove the decline in the relative price of IT investment $\xi^{I}$ and instead set it equal to its value in the first period of our sample. The decline in $\xi^{I}$ increases capitalists' investment rate, which as the third term of equation (31) shows, leads to a decline in the relative consumption of capitalists. We conclude that IT-specific technological change lowered inequality and this conclusion is robust across

\footnotetext{
${ }^{48}$ We note that the effects of $A^{L}$ on $C^{K} / C^{L}$ change significantly when we begin our analysis in the mid 1980s. This because the patterns of inferred $A^{L}$ vary significantly both across cases and across values of $\sigma$ when we begin our analysis in the mid 1980s, as shown in Figure 13.
} 
different cases and values of the elasticity. On the other hand, the effects on $s_{L}^{Q}$ depend on the elasticity of substitution. Given constant markups, equation (30) shows that a decline in $\xi^{I}$ leads to a decline in $s_{L}^{Q}$ when $\sigma>1$ because $R^{Q}$ declines and the opposite when $\sigma<1$. Table 3 shows that, for $\sigma=1.25$, the decline in $\xi^{I}$ contributes to a decline in the labor share between 2.4 and 2.9 percentage points. ${ }^{49}$ By contrast if $\sigma=0.75$, the decline in $\xi^{I}$ increases the labor share by roughly 2.7 to 3.3 percentage points. As shown in Table 4 , in all cases the decline in the relative price of IT causes business output to rise between 0.18 and $0.21 \log$ point when $\sigma=1.25$ and between 0.13 and $0.15 \log$ point when $\sigma=0.75$.

The other rows in Tables 2, 3, and 4 present summary statistics for counterfactuals in which we keep constant at their 1960 values IT capital-augmenting technology $\left(A^{K}\right.$ and $\left.\nu^{I}\right)$, the relative price of non-IT investment $\left(\xi^{N}\right)$, non-IT capital-augmenting technology $\left(A^{K}\right.$ and $\left.\nu^{N}\right)$, labor supply $(L)$, and capital taxes $\left(\tau^{k}\right)$. We find significant declines in $C^{K} / C^{L}$ and increases in $Q$ in response to IT capital-augmenting technology $\left(A^{K}\right.$ and $\left.\nu^{I}\right)$, with the effects being the largest in Case K. Under an elasticity $\sigma>1$, IT capital-augmenting technology also accounts for large declines in $s_{L}^{Q}$. The increase in labor supply $L$ relative to the 1960s contributed to a decline in $C^{K} / C^{L}$ and an increase in $Q$ of roughly $0.18 \log$ point in all three cases. Finally, the decline in capital taxes $\tau^{k}$ since the 1960s raised the after-tax return on saving and the consumption growth of capitalists and is associated with an increase in $C^{K} / C^{L}$ between 0.08 and $0.16 \log$ point across cases.

\section{Conclusion}

U.S. GDP deviates significantly from the sum of measured payments to labor and imputed rental payments to capital. This deviation, or what we call factorless income, could reflect economic

\footnotetext{
${ }^{49}$ In a model with a single investment good, Karabarbounis and Neiman (2014) argued that the decline in the aggregate price of investment goods led to a decline in the labor share of roughly 2.5 percentage points. Our results here with multiple types of capital are broadly consistent with Eden and Gaggl (2018) who estimate a production function with IT and non-IT capital and argue that the decline in the relative price of IT accounts for roughly half of the decline in the U.S. labor share. Recent work by Autor and Salomons (2018) presents evidence across countries and industries that relates productivity-enhancing technological advances (potentially caused by the adoption of industrial robots and patenting flows) to declines in the labor share after the 1980s.
} 
profits, missing capital, or a gap between the return on risk-free bonds and the cost of capital that firms perceive when making their investment decisions. In this paper we assess the plausibility of each of these strategies in allocating factorless income and demonstrate their implications for our understanding of macroeconomic outcomes such as functional inequality, factor shares, productivity, and growth.

We have laid out our skepticism of Case П. Future work embracing this interpretation must articulate the mechanism by which a lower opportunity cost of capital is associated with higher markups and greater monopoly power. Further, if Case $\Pi$ forms the basis for new calls for antitrust enforcement, it should be acknowledged that the logic for such calls was equally present in the 1960s and 1970s. We have similarly laid out our skepticism of Case $K$ and emphasize that future work embracing this interpretation must take a broad view of what constitutes unmeasured capital, potentially including forms of missing investment that far predate the IT revolution. However, we also recognize that more flexible analyses of missing capital may be able to cast this possibility in a more favorable light. We find Case $R$ the most promising and hope future work explores reasons why simple measures of the rental rate of capital might deviate from the rental rate that firms face when making their investment decisions. While we have considered the three methodologies in isolation to document with clarity their individual strengths and weaknesses, a direction for future research is to consider combinations of these methodologies.

Our interest in factorless income emerged from our prior work documenting a decline in the global labor share and associating it with capital-specific technological change. What do these three cases teach us about the labor share decline? Our skepticism about Case $\Pi$ corroborates the view in Karabarbounis and Neiman (2014) that while rising markups likely contributed, much of the decline remains to be explained by technological change. Our scepticism about Case $K$ alleviates measurement concerns arising from missing output and reaffirms our measures of the labor share decline. Case $R$ most closely approximates an environment with a stable opportunity cost of capital and in which IT-capital prices drive a significant amount of the variation in rental 
rates and factor shares, as in our earlier analyses.

Finally, though this study focuses on the United States, we note that the labor share decline has been a global phenomenon impacting developed countries in Continental Europe and Scandinavia and emerging economies such as China, India, and Mexico. We maintain our view that much can be learned from comparisons across this diverse set of experiences. In some countries like the United States, investment spending has been relatively low in recent decades. In others, like China, investment has been increasing. We hope our methodology will be applied to many economies and that the study of factorless income around the world enhances our understanding of global changes in technology, product markets, and capital markets.

\section{References}

Atkeson, A., And P. Kehoe (2005): "Modeling and Measuring Organization Capital," Journal of Political Economy, 113(5), 1026-1053.

Autor, D., D. Dorn, L. F. Katz, C. Patterson, and J. Van Reenen (2017): "Concentrating on the Fall of the Labor Share," National Bureau of Economic Research Working Paper.

Autor, D., And A. Salomons (2018): "Is Automation Labor-Displacing? Productivity Growth, Employment, and the Labor Share," Brookings Papers on Economic Activity.

BARKAI, S. (2016): "Declining Labor and Capital Shares," University of Chicago Working Paper.

Basu, S., And J. Fernald (1997): "Returns to Scale in US Production: Estimates and Implications," Journal of Political Economy, 105(2), 249-283.

BAsu, S., AND J. G. FERnAld (2002): "Aggregate productivity and aggregate technology," European Economic Review, 46(6), 963-991.

Bils, M., P. Klenow, and B. Malin (2018): "Resurrecting the Role of the Product Market Wedge in Recessions," American Economic Review, 108(4-5), 1118-1146. 
Caballero, R., E. Farhi, and P.-O. Gourinchas (2017): "Rents, Technical Change, and Risk Premia Accounting for Secular Trends in Interest Rates, Returns on Capital, Earning Yields, and Factor Shares," American Economic Review, 107(5), 614-620.

Caselli, F., and J. Feyrer (2007): "The Marginal Product of Capital," Quarterly Journal of Economics, 122(2), 535-568.

Chen, P., L. Karabarbounis, and B. Neiman (2017): "The Global Rise of Corporate Saving," Journal of Monetary Economics, 89, 1-19.

Chirinko, R. (2008): " $\sigma$ : The Long and Short of It," Journal of Macroeconomics, 30, 671-686.

Corrado, C., C. Hulten, and D. Sichel (2009): "Intangible Capital and US Economic Growth," Review of Income and Wealth, 55(3), 661-685.

Dao, M. C., M. Das, Z. Koczan, and W. Lian (2017): "Why is Labor Receiving a Smaller Share of Global Income? Theory and Empirical Evidence," International Monetary Fund Working Paper.

De Loecker, J., And J. Eeckhout (2017): "The Rise of Market Power and the Macroeconomic Implications," National Bureau of Economic Research Working Paper.

De Loecker, J., and F. Warzynski (2012): "Markups and Firm-Level Export Status," American Economic Review, 102(6), 2437-2471.

Duarte, F., and C. Rosa (2015): "The Equity Risk Premium: A Review of Models," Federal Reserve Bank of New York Staff Report.

Eden, M., and P. Gaggl (2018): "On the Welfare Implications of Automation," Review of Economic Dynamics, 29, 15-43.

Eggertsson, G., J. Robbins, and E. Wold (2018): "Kaldor and Piketty's Facts: The Rise of Monopoly Power in the United States," National Bureau of Economic Research Working Paper.

Eisfeldt, A., and D. Papanikolaou (2013): "Organization Capital and the Cross-Section of Expected Returns," Journal of Finance, 68(4), 1365-1406.

Elsby, M. W., B. Hobijn, And A. Şahin (2013): "The Decline of the US Labor Share," Brookings Papers on Economic Activity, 2013(2), 1-63. 
Fama, E., And K. French (2002): "The Equity Premium," Journal of Finance, 57, 637-659.

Fernald, J., and B. Neiman (2011): "Growth Accounting with Misallocation: Or, Doing Less with More in Singapore," American Economic Journal: Macroeconomics, 3(2), 29-74.

Gali, J., M. Gertler, and D. Lopez-Salido (2007): "Markups, Gaps, and the Welfare Costs of Business Fluctuations," Review of Economics and Statistics, 89(1), 44-59.

Gollin, D. (2002): "Getting Income Shares Right," Journal of Political Economy, 110(2), $458-474$.

Gomme, P., B. Ravikumar, and P. Rupert (2011): "The Return to Capital and the Business Cycle," Review of Economic Dynamics, 14, 262-278.

Greenwood, J., S. Hercowitz, and P. Krusell (1997): "Long-Run Implications of Investment-Specific Technological Change," American Economic Review, 87(3), 342-362.

Gutiérrez, G., and T. Philippon (2017): "Declining Competition and Investment in the U.S.," National Bureau of Economic Research Working Paper.

Guvenen, F., R. Mataloni, D. Rassier, and K. Ruhl (2017): "Offshore Profit Shifting and Domestic Productivity Measurement," National Bureau of Economic Research Working Paper.

Hall, R. (1990): "Invariance Properties of Solow's Productivity Residual," in Growth/Productivity/Unemployment: Essays to Celebrate Bob Solow's Birthday, pp. 71-112. (2001): "The Stock Market and Capital Accumulation," American Economic Review, 91(5), 1185-1202.

Hall, R., and D. Jorgenson (1967): "Tax Policy and Investment Behavior," American Economic Review, 57(3), 391-414.

Hartman-Glaser, B., H. Lustig, and M. Zhang (2016): "Capital Share Dynamics When Firms Insure Workers," National Bureau of Economic Research Working Paper.

Jagannathan, R., E. McGrattan, and A. Scherbina (2000): "The Declining U.S. Equity Premium," Federal Reserve Bank of Minneapolis Quarterly Review. 
Jorda, O., K. Knoll, D. Kuvshinov, M. Schularick, and A. Taylor (2017): "The Rate of Return on Everything, 1870-2015," National Bureau of Economic Research Working Paper.

Karabarbounis, L. (2014): "The Labor Wedge: MRS vs. MPN," Review of Economic Dynamics, 17(2), 206-223.

Karabarbounis, L., and B. Neiman (2014): "The Global Decline of the Labor Share," Quarterly Journal of Economics, 129(1), 61-103.

Kehrig, M., and N. Vincent (2017): "Growing Productivity Without Growing Wages: The Micro-Level Anatomy of the Aggregate Labor Share Decline," ERID Working Paper.

Koh, D., R. Santaeulàlia-Llopis, and Y. Zheng (2016): "Labor Share Decline and Intellectual Property Products Capital," University of Arkansas Working Paper.

MCDaniel, C. (2009): "Updated Tax Series OECD 1950-2009," http: // www. caramcdaniel. com/researchpapers.

McGrattan, E., and E. Prescott (2005): "Taxes, Regulations, and the Value of U.S. and U.K. Corporations," Review of Economic Studies, 72(3), 767-796.

Nekarda, C., And V. Ramey (2013): "The Cyclical Behavior of the Price-Cost Markup," National Bureau of Economic Research Working Paper.

Oberfield, E., and D. Raval (2014): "Micro Data and Macro Technology," Princeton University Working Paper.

Piketty, T., And G. Zucman (2014): "Capital is Back: Wealth-Income Ratios in Rich Countries 1700-2010," Quarterly Journal of Economics, 129(3), 1255-1310.

Rognlie, M. (2015): "Deciphering the Fall and Rise in the Net Capital Share: Accumulation or Scarcity?," Brookings Papers on Economic Activity, Spring(1), 1-69.

Rotemberg, J., and M. Woodford (1995): "Dynamic General Equilibrium Models With Imperfectly Competitive Product Markets," in Frontiers of Business Cycle Research. Princeton University Press.

Smith, M., D. Yagan, O. Zidar, and E. Zwick (2017): "Capitalists in the 21st Century," University of Chicago Working Paper. 
Traina, J. (2018): "Markup Estimation Using Financial Statements: Cost of Goods Sold vs. Operating Expense," University of Chicago Working Paper.

Vollrath, D. (2017): "An Update on the Profits from Housing," https://growthecon.com/ blog/Ricardian-Housing/.

Weitzman, M. (1976): "On the Welfare Significance of National Product in a Dynamic Economy," Quarterly Journal of Economics, 90, 156-162. 